\title{
Dissociation of Visual and Saccade-Related Responses in Superior Colliculus Neurons
}

\author{
LAWRENCE E. MAYS AND DAVID L. SPARKS \\ Neurosciences Program and Department of Psychology, University of Alabama, \\ Birmingham, Alahama 35294
}

\section{SUMMARY AND CONCLUSIONS}

1. Single-unit activity was recorded from the superior colliculus (SC) of monkeys trained to look to visual targets presented on an oscilloscope screen. On one task, target localization required that information concerning the retinal position of the target be combined with information concerning current or future eye position. This task also permitted a dissociation between the site of retinal stimulation and the metrics of the saccade triggered by the stimulation.

2. Vigorous visual responses of superficial SC neurons may occur that do not result in the activation of underlying saccade-related cells. The activity of these ncurons signals the occurrence of a visual stimulus, whether or not the stimulus is selected for foveal viewing.

3. Saccade-related (SR) discharges of most intermediate and deep-layer SC neurons precede saccades with particular vectors, regardless of the region of retinal activation initiating the saccade. The discharge of these neurons is tightly coupled to saccade onset, even if changes in eye position have occurred since target appearance. Thus, the discharge of these SR neurons must occur after retinal error and eye-position signals have been combined to compute the necessary saccade vector. For most SR neurons, direct retinal activation of overlying visual neurons had no effect on either the vigor or probability of a SR discharge. The discharge of overlying visual cells is neither necessary nor sufficient to activate most SR cells.

4. The discharge of some SR cells is dependent on prior activation of overlying visual cells. Of 53 SR cells, only 3 were completely dependent on visual stimulation, while another 8 discharged less vigorously if corresponding visual activation failed to occur.

5. About one-quarter of the SR cells showed long-lead preburst activity. This activation was characterized by a low level of firing, which began after the saccade signal and continued until a saccade-linked burst occurred.

6 . Cells were isolated that were visually responsive yet discharged prior to saccades in the absence of appropriate retinal stimulation. No component of the discharge of these quasi-visual (QV) cells appeared to be motor in the usual sense. The activity of these neurons appears to reflect eyeposition error (the difference between actual and desired eye position) and to hold this information in spatial register until a saccade occurs or is canceled.

7. It is concluded that the presumed linkage, implied in earlier versions of the foveation hypothesis, between the superficial layers (receiving direct retinal inputs) and the deeper layers of the SC is not necessary for the activation of SR neurons. Results suggest that the SC must generate or receive a signal that combines retinal error and eye-position information. These findings are discussed in terms of current models of the saccadic-control system.

\section{INTRODUCTION}

Schiller and Koerner (15) hypothesized that one function of the superior colliculus (SC) is to code the location of a visual target relative to the fovea and to trigger a saccade that will produce foveal acquisition of the target. Evidence for this hypothe- 
sis is derived, primarily, from chronic microelectrode and electrical stimulation experiments in the monkey. Neurons in the superficial layers of the SC discharge in response to visual stimuli in the contralateral visual field $(3,6,7,15,16,25)$. Below these cells, in the intermediate and deeper layers, neurons are found that discharge before saccades with specific amplitudes and directions $(11,15,16,21,24,25)$. Electrical stimulation of the deeper layers elicits short-latency saccades corresponding to the movement fields (the range of eye movements that alters the discharge frequency of a neuron) of cells recorded at the stimulation site (16). The map of the movement fields of the deeper neurons corresponds to the retinotopic map of the receptive fields of the overlying visual neurons (12). Visually triggered activity in the superficial layers is assumed to activate corresponding regions of the deeper layers and, thereby, to produce a saccade that brings the foveal projection onto the region of the visual field containing the target. According to this hypothesis, the location of a saccade target is specified as a retinal-error signal (the location of a retinal image with respect to the fovea).

In contrast, recent models of the saccadic-control system $(2,13,27)$ assume that saccade target-position signals are in a head or body frame of reference. This assumption is made to account for the findings that, in the dark, the oculomotor system can produce accurate saccades to acquire the source of a sound (26) or the remembered locations of visual targets (1, 10). Hallet and Lightstone (8) demonstrated that a visual target flashed during a primary saccade can be used to elicit a subsequent saccade back to the position of the target in space. Since the position of the eye changed after the flash, the retinal-error signal alone cannot specify current target position. Retinal error must be combined with eyeposition signals (direction and amplitude of the intervening saccade) to compute the coordinates of the acquisition saccade.

The major purpose of the present experiment was to monitor the activity of SC neurons in monkeys trained on a modification of the Hallet and Lightstone task. If SC neurons discharge prior to saccades triggered by this task, then the SC must generate or receive a signal that combines retinal error and information concerning current or future eye position. One consequence of using this task was to disrupt the presumed linkage between visually triggered activity in the superficial layers and saccade-related activity in the deeper layers. Thus, a secondary purpose of the experiment was to examine the functional linkage between superficial and deeper layers of the SC. A preliminary report of these results has been published previously (22).

\section{METHODS}

\section{Surgical and recording procedures}

Six rhesus monkeys (Macaca mulatta) weighing from 2.5 to $4.0 \mathrm{~kg}$ underwent three sterile surgical procedures under barbiturate anesthesia. First, four stainless steel bolts were implanted in each monkey's skull. A lightweight aluminum frame, attached to these bolts, provided a means of immobilizing the monkey's head during training and recording sessions. In the second surgical procedure, a coil of fine wire was surgically implanted around one eye. This coil allowed eye position to be measured using an electromagnetic search-coil method (5) with a sensitivity of at least $0.25^{\circ}$. Following $4-8 \mathrm{wk}$ of behavioral training, a stainless steel receptacle for a microdrive was secured to the skull in the third procedure. The receptacle was positioned over a $15-\mathrm{mm}$-diameter opening in the skull centered on the midline at stereotaxic zero (anterior-posterior). During recording sessions, a glass-insulated tungsten microelectrode was advanced into either superior colliculus by means of a remotely operated hydraulic microdrive. Extracellular potentials were amplified by a high-impedance amplifier and filtered above $6 \mathrm{kHz}$ and below $300 \mathrm{~Hz}$. Spike potentials, horizontal and vertical eye positions, and digital codes representing stimulus and response events were recorded on analog magnetic tape.

\section{Behavioral training}

Monkeys were kept on a 23-h water-deprivation schedule for 6 days each week. During behavioral training sessions, the monkey, seated in a primate chair, was placed in an electrostatically shielded, sound-attenuated chamber. The head-restraint frame was clamped to a rigid bar, which was, in turn, attached to the frame of the chamber. This allowed the monkey's head to be fixed in the same position in the magnetic field each day and simplified eye-position calibration. Each monkey was trained to look at a small $\left(0.1^{\circ}\right)$ spot on a large-screen oscilloscope 
for a water reward. The oscilloscope (HewlettPackard 1310 with P31 phosphor or HP 1321 with P47 phosphor) provided a viewing area of at least $50^{\circ}$ (horizontal) by $40^{\circ}$ (vertical) when placed $35 \mathrm{~cm}$ from the monkey. The location of the target spot on the screen and the water reinforcement were controlled by a PDP-8I computer. Details of the computer system and training procedures have been previously described $(20,21)$.

After preliminary training, all monkeys learned two tasks: a single-saccade task and a doublesaccade task. Additionally, three of the monkeys were trained on a visual-probe task and a delayed-saccade task. These tasks were performed under photopic illumination and the target spot was adjusted to be as dim as possible yet still permit adequate tracking performance.

SINGLE-SACCADE $(o \rightarrow$ A) TRIALS. On single-saccade trials (Fig. 1A), an initial fixation target $(\mathrm{O})$ was presented at the center of the oscilloscope screen. If the target was acquired within $500 \mathrm{~ms}$ and fixation was maintained for a variable period (1-3 s), target $O$ was extinguished and target $\mathrm{A}$ appeared at an eccentric position (usually $5-15^{\circ}$ from target $\mathrm{O}$ ). If target $\mathrm{A}$ was acquired within $500 \mathrm{~ms}$ and fixation maintained for $1 \mathrm{~s}$, reinforcement was delivered on a continuous ratio schedule.

DOUBLE-SACCADE $(\mathrm{O} \rightarrow \mathrm{B} \rightarrow \mathrm{C})$ TRIALS. After 2-4 wk of training on the single-saccade task, monkeys learned the double-saccade task (Fig. $1 C$ ). In this task, after fixation of the initial target $(\mathrm{O})$ for a variable period, the offset of the center fixation target was followed by successive presentations of targets $B$ and $C$. The total duration of targets $B$ and $C$ was less than the reaction time of the monkey (i.e., both $B$ and $C$ were off before a saccade occurred). Nevertheless, reward was contingent on making a saccade to position $B$ within $300 \mathrm{~ms}$ and a second saccade from $\mathrm{B}$ to $\mathrm{C}$ before an additional $500 \mathrm{~ms}$ elapsed. Thus, two saccades were made in succession; the first from position $\mathrm{O}$ to $\mathrm{B}$ and the second from $\mathrm{B}$ to $\mathrm{C}$. Although the double-saccade task is more complex than the single-saccade task, monkeys did not require special shaping or preliminary training. It was not unusual for a monkey to perform this task properly the first time it was presented.

Figure 1 shows how the double-saccade task can be used to dissociate visual and motor activation of SC cells. On single-saccade trials (Fig. 1A), the onset of target $\mathrm{A}$ (in the right visual field) will elicit a visual response in the superficial layers of the left SC (Fig. 1C, site 1). Later, a discharge in the underlying layers will occur (Fig. 1C, site 2) just prior to the saccade from $\mathrm{O}$ to A. On double-saccade trials (Fig. $1 B$ ), the onset of stimulus $B$ in the left visual field will elicit a visual response in the superficial layers of the right $\mathrm{SC}$ at site 1 (Fig. $1 D$ ). If fixation of $\mathrm{O}$ is maintained, the onset of stimulus $\mathrm{C}$ will then elicit a response in the right $\mathrm{SC}$ at site 2 . A short time later, a premotor discharge (site 3 ) will occur in the deeper layers of the right SC prior to the leftward $\mathrm{O} \rightarrow \mathrm{B}$ saccade. If the sum of the durations of targets $\mathrm{B}$ and $\mathrm{C}$ is less than about $150 \mathrm{~ms}$, then all visual targets will be off prior to the saccade from $\mathrm{O}$ to $\mathrm{B}$. A premotor discharge in the left SC (site 4) should precede the rightward saccade from B to C. Since no visual targets appeared in the right visual field, presumably there will be no corresponding visual activation of the left SC.

Typically, on double-saccade trials, the B $\rightarrow$ $C$ saccade was in the movement field of saccaderelated ncurons and on acquisition of $\mathrm{B}, \operatorname{target} \mathrm{C}$, if present, was in the receptive fields of visual neurons. However, double-saccade trials were often used in which the B $\rightarrow$ C saccade was not in the movement field and stimulus $C$ was not in the receptive field of the neuron being studied. These trials provided a control for the nonspecific effects of the double-saccade task. Also, double-saccade trials were used in which target A was in the cell's receptive field when the animal was looking at $\mathrm{O}(\mathrm{O} \rightarrow \mathrm{B} \rightarrow \mathrm{A}$ trials $)$. This trial allowed visual responsiveness to be assessed in the absence of a direct movement to the target.

A modification of the double-saccade trial was frequently used. On this trial type $(\mathrm{O} \rightarrow \mathrm{B} \rightarrow$ $\overline{\mathrm{O}})$, after a variable fixation of the center target (O), target $\mathrm{O}$ was extinguished and followed by a brief appearance ( $100 \mathrm{~ms}$ or less) of target $\mathrm{B}$. The bar over $\mathrm{O}$ indicates that target $\mathrm{O}$ was not relighted, but the monkey is still required to look to the location of $O$. The monkeys learned that a brief duration of $\mathrm{B}$ required a saccade $(\mathrm{O} \rightarrow$ $\mathrm{B})$ to position $\mathrm{B}$ and a second saccade $(\mathrm{B} \rightarrow \mathrm{O})$ back to the previous position of target $\mathrm{O}$ to produce a reward. The $\mathrm{B} \rightarrow \mathrm{O}$ saccade was usually in the cell's movement field. These trials were used to control for oscilloscope persistence since by the time the eyes were directed at B, the initial fixation target $(\mathrm{O})$ would have been off for at least $140 \mathrm{~ms}$ (the latency of the monkey to look from $\mathrm{O}$ to $\mathrm{B})$.

VISUAL-PROBE $(\mathrm{O} \rightarrow \mathrm{O}+\mathrm{A} \rightarrow \mathrm{O})$ TRIALS. On visual-probe trials, the center fixation target (O) was present for the total duration of the trial. Monkeys were required to maintain fixation of the center target $(\mathrm{O})$ even though another target (A) was presented briefly. The designation of "O $+A$ " indicates that targets $\mathrm{O}$ and $\mathrm{A}$ appear simultaneously. Inclusion of this trial type permitted the receptive fields of visually responsive neurons to be plotted in the absence of saccades to acquire the target. 

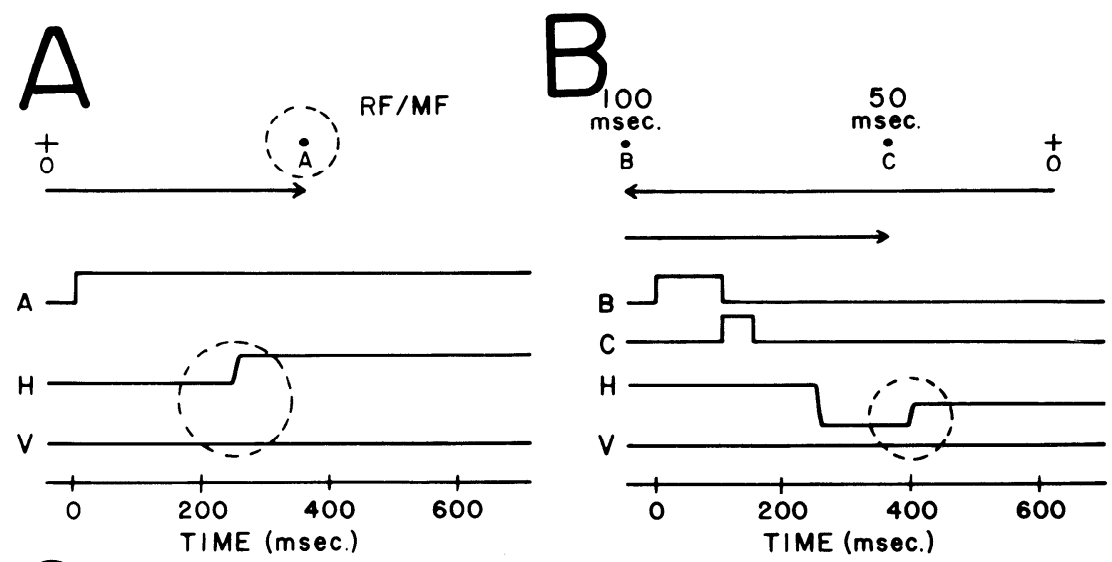

D
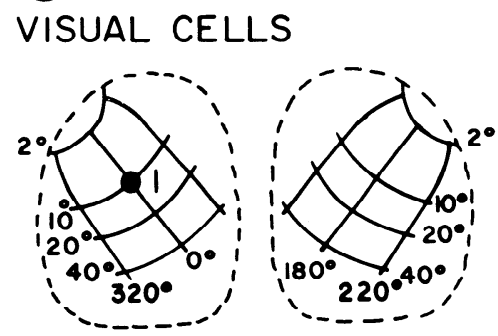

VISUAL CELLS
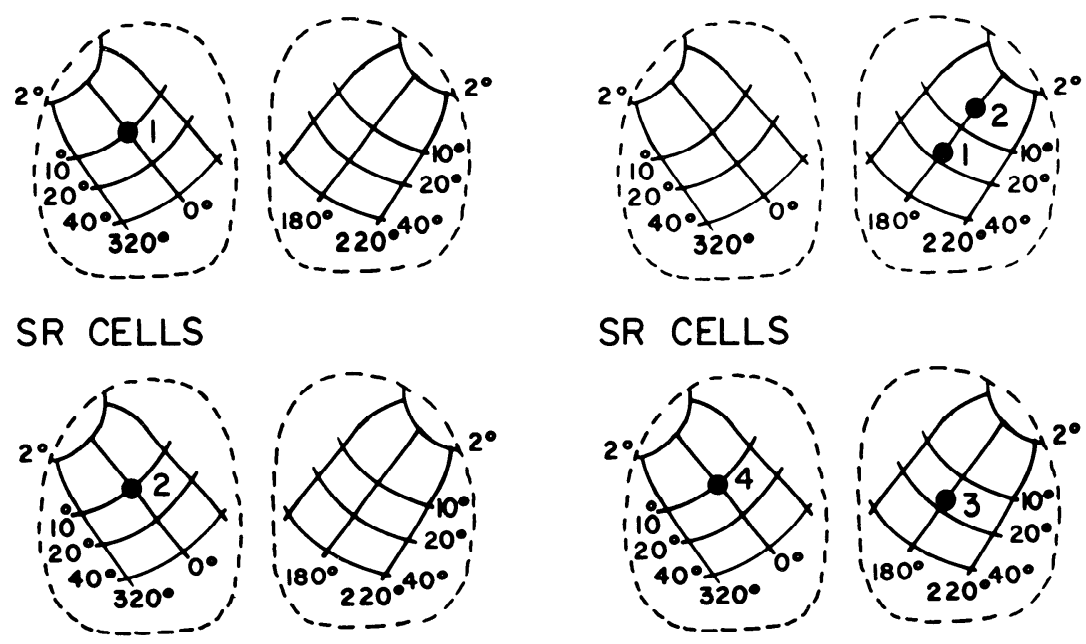

FIG. 1. Schematic representation of $\mathrm{O} \rightarrow \mathrm{A}$ single-saccade and $\mathrm{O} \rightarrow \mathrm{B} \rightarrow \mathrm{C}$ double-saccade trial types. $A$ shows target onset and horizontal and vertical eye position for a rightward saccade. After fixation of target $\mathrm{O}$, target $\mathrm{A}$, in the right visual field, appeared immediately after the fixation target was extinguished. Following a response-latency period of from 150 to $300 \mathrm{~ms}$, a rightward saccade was made to target $A$. $C$ represents areas of greatest neuronal activity within the SC during this trial. About $70 \mathrm{~ms}$ after the onset of the target at $\mathrm{A}$, a visual response occurs in the superficial layers of the left SC (site 1). About $20 \mathrm{~ms}$ before the saccade from $O$ to $A$, saccade-related cells in the intermediate and deeper layers of the underlying left SC (site 2) generate a vigorous burst of activity. Figure $1 B$ shows stimulus and response events on an $\mathrm{O} \rightarrow \mathrm{B} \rightarrow \mathrm{C}$ trial. After fixation of target $\mathrm{O}$, target $\mathrm{O}$ was extinguished, target $\mathrm{B}$ appeared for $100 \mathrm{~ms}$, and finally, target $\mathrm{C}$ appeared for $50 \mathrm{~ms}$. Targets $\mathrm{B}$ and $\mathrm{C}$ were in the left visual field. After target $C$ was extinguished, a saccade was made to location $B$ and was followed by a saccade from $B$ to $C$. Note that the saccade from $B$ to $C$ had the same direction and amplitude as the saccade from $\mathrm{O}$ to A. $D$ is a plausible representation of the neuronal activity occurring within the SC during this trial. About $70 \mathrm{~ms}$ after target $\mathrm{B}$ onset, visual activation of an area in the right superficial layers occurs (site 1). About $70 \mathrm{~ms}$ after the onset of C, another area of the right superficial layers (site 2) is activated. Just before the saccade from $\mathrm{O}$ to B, a saccade-related burst occurs in the intermediate layers of the right SC (site 3). Finally, a saccade-related burst occurs in the left SC (site 4) prior to the saccade from B to C. Note that this was the same area of the left SC that was activated prior to the $\mathrm{O} \rightarrow \mathrm{A}$ saccade. Unlike the single-saccade trial, all visual stimuli appeared in the left visual field, and all visual responses should be confined to the right SC.

DELAYED-SACCADE $(\mathrm{O} \rightarrow \mathrm{O}+\mathrm{A} \rightarrow \mathrm{A})$ TRIALS. On delayed-saccade trials, the animal was permitted $500 \mathrm{~ms}$ to acquire the initial center target $(\mathrm{O})$. After a variable-fixation interval, a second target (A) appeared concurrently with target $\mathrm{O}$ but the trial was terminated, without reinforcement, if the animal failed to maintain fixation of target $O$. After another variable delay, 
target $\mathrm{O}$, but not target $\mathrm{A}$, was extinguished. If an $\mathrm{O} \rightarrow \mathrm{A}$ saccade occurred within $500 \mathrm{~ms}$ and was followed by a 1-s fixation of A, reinforcement occurred. This delayed-saccade task was used to test for the presence of visual and saccade-related discharges. Since the visual response of most SC neurons is phasic, usually the visual and motor components of a discharge could be separated by requiring a delay between target onset and the acquisition saccade.

\section{Data collection and analysis}

Whenever an SC cell was isolated and appeared to be stable, its receptive and/or movement field was determined using single-saccade $(\mathrm{O} \rightarrow \mathrm{A})$ or delayed-saccade $(\mathrm{O} \rightarrow \mathrm{O}+\mathrm{A} \rightarrow \mathrm{A})$ trials in which the position of $A$ was varied systematically. Next, a series of double-saccade $(\mathrm{O} \rightarrow \mathrm{B} \rightarrow \mathrm{C}$ or $\mathrm{O} \rightarrow \mathrm{B} \rightarrow \overline{\mathrm{O}})$ trials was intermixed, randomly, with single-saccade $(\mathrm{O} \rightarrow \Lambda$, $\mathrm{O} \rightarrow \mathrm{B}$, and $\mathrm{O} \rightarrow \mathrm{C}$ ) trials. The duration of targets on double-saccade trials was varied. For most cells, several different positions were used for targets $\mathrm{A}, \mathrm{B}$, and $\mathrm{C}$, although the vector between targets $B$ and $C$ was usually the same as that of $\mathrm{O}$ and $\mathrm{A}$. Typically, data from $10-20$ replications of each trial type were collected. For most cells, the receptive or movement field was then replotted. Frequently, the data from one cell consisted of over 500 trials and required $1-2 \mathrm{~h}$ to collect. Only data from cells that remained stable for a relatively complete experimental series are reported.

Computer-generated plots of instantaneous spike frequency, the reciprocal of interspike interval (measured to the nearest $100 \mu \mathrm{s}$ ), horizontal and vertical eye position, and target onset and offset were obtained for each trial. Single-trial plots are used to illustrate the properties of the neurons examined since averaged histograms tend to obscure the relationships between neuronal events (i.e., the onset, offset, and peak instantaneous frequency) and saccade and target events. Generally, the trials shown are representative of at least 10 similar trials.

\section{Electrode localization}

Electrode location in the rostrocaudal and medial-lateral planes was estimated by comparing the plots of movement (receptive) fields with readings from the $X-Y$ micropositioner. The well-defined retinotopic organization of the SC allowed the movement (receptive) fields of cells that would be encountered at any $X-Y$ coordinate to be predicted with reasonable accuracy. Electrode depth was estimated by recording the microdrive micrometer reading at which the first $\mathrm{SC}$ activity was observed and again whenever a cell was recorded. On the last week of recording from an animal, from one to three small electro- lytic lesions were made at the location of cells of interest. Coronal sections of the SC stained with cresyl violet allowed these sites to be localized. Lesion sites were used with microdrive readings to reconstruct electrode placements.

\section{RESULTS}

Complete data were obtained for $108 \mathrm{SC}$ neurons. Based on responses on both single- and double-saccade trials, these cells were placed in one of four major categories. The criteria for placing cells in each category are described below.

\section{Visual cells}

Neurons placed in this category met the following criteria: $l$ ) each displayed a discharge tightly coupled to the onset of a stimulus in the receptive field; 2 ) they did not show any saccade-related discharge; and 3 ) they did not fire on those doublesaccade trials in which no stimulus appeared in the receptive field. Seventeen cells met these criteria. Most visual cells were among the first cells encountered on entering the SC.

The response of a typical visual cell is shown in Fig. 2. This cell was encountered within the superficial layers of the right SC. Figure $2 A$ is a schematic representation of the cell's receptive field (circle) and target positions (O, A, B, and $\mathrm{C})$. The target locations are given in polar coordinates ( $\theta$, angle; $\mathrm{R}$, radius) with target $\mathrm{O}$ as the origin. On single-saccade $(\mathrm{O} \rightarrow \mathrm{A})$ trials with target $A$ in the receptive field, a vigorous burst of neuronal activity occurred about $80 \mathrm{~ms}$ after target A onset (Fig. 2C). This relatively long latency is probably the result of the use of a very low-contrast target since brighter targets yielded shorter latency responses. The timing of the burst was always closely linked to stimulus onset, not to saccade onset. The burst of activity also occurred on $\mathrm{O} \rightarrow \mathrm{O}+\mathrm{A} \rightarrow \mathrm{O}$ visualprobe trials in which no saccade occurred.

On double-saccade $(\mathrm{O} \rightarrow \mathrm{B} \rightarrow \mathrm{C})$ trials in which the $\mathrm{B} \rightarrow \mathrm{C}$ saccade was equivalent to the $\mathrm{O} \rightarrow \mathrm{A}$ saccade, no alteration in spike activity was observed if targets $B$ and $C$ were off before the saccade to B occurred (Fig. 2B). If, when the monkey looked at position $B$, target $C$ was still on and in the cell's receptive field, a discharge occurred about $70 \mathrm{~ms}$ after the acquisition of target B (Fig. 2D). These responses are expected 

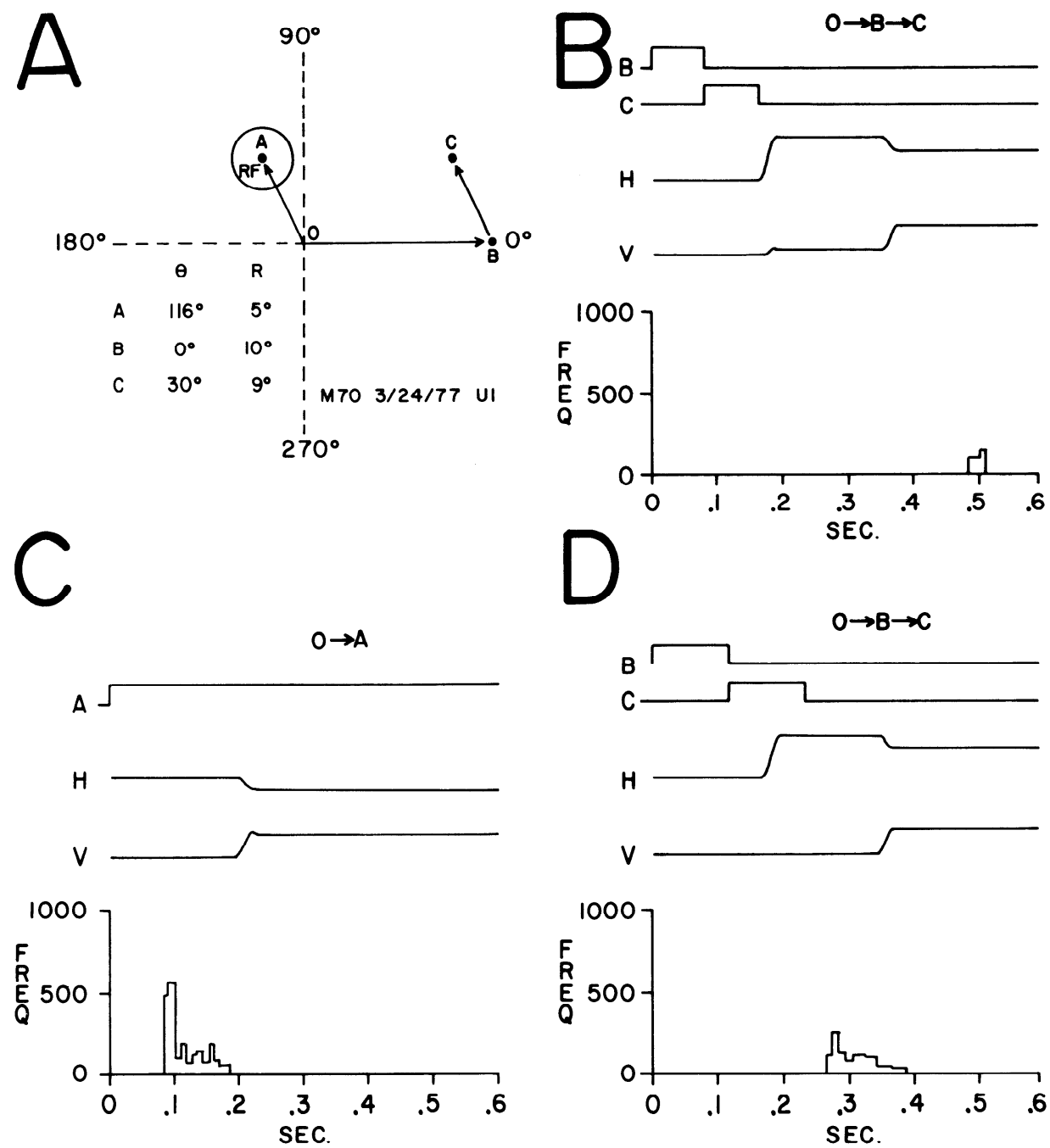

FIG. 2. Typical response of a visual cell on single- and double-saccade trials. $A$ is a schematic representation of the receptive field (centered about location $A$ ) of this cell, and of target locations and saccade vectors. During fixation of target $\mathrm{O}$, targets $\mathrm{B}$ and $\mathrm{C}$ were in the right visual field and target $\mathrm{A}$ was in the left visual field. Note that the direction and distance of target $\mathrm{C}$ from target $\mathrm{B}$ was the same as that of target $\mathrm{A}$ from fixation target $\mathrm{O}$. $C$ shows target onset, horizontal and vertical eye position, and instantaneous spike frequency for a single saccade to target A. On this and other figures, rightward eye movements are shown as upward deflections of the horizontal trace; upward movements, as upward deflections of the vertical trace. Note the burst of neuronal activity beginning about $75 \mathrm{~ms}$ after the appearance of target $\mathrm{A}$. $B$ shows the response of the same cell on an $\mathrm{O} \rightarrow \mathrm{B} \rightarrow \mathrm{C}$ trial. Durations of targets at $B$ and $C$ were so brief $(80 \mathrm{~ms}$ each) that all targets were off before the eye left the fixation point at $\mathrm{O}$. Although the $\mathrm{B} \rightarrow \mathrm{C}$ saccade had approximately the same amplitude and direction as the $\mathrm{O} \rightarrow \mathrm{A}$ saccade, there was no significant activation of the cell. This is in contrast to the $\mathrm{O} \rightarrow \mathrm{B} \rightarrow \mathrm{C}$ trial shown in $D$ in which target $\mathrm{C}$ was still on after the monkey looked to position $\mathrm{B}$. A visual response was observed about $70 \mathrm{~ms}$ after the eye was directed at B.

of cells that respond only to the appearance of a stimulus in the receptive field. The occurrence of a saccade alone is not sufficient to activate these cells.

Saccade-related cells

Saccade-related (SR) cells had the following characteristics: 1 ) their discharge was clearly associated with saccade onset; and 2 ) visual responses, if present, were weak (e.g., three spikes) and the receptive ficld was much smaller than the movement field. Fifty-three cells were placed in this category. Lesions placed at the site of recording of SR neurons were localized in the inter- 


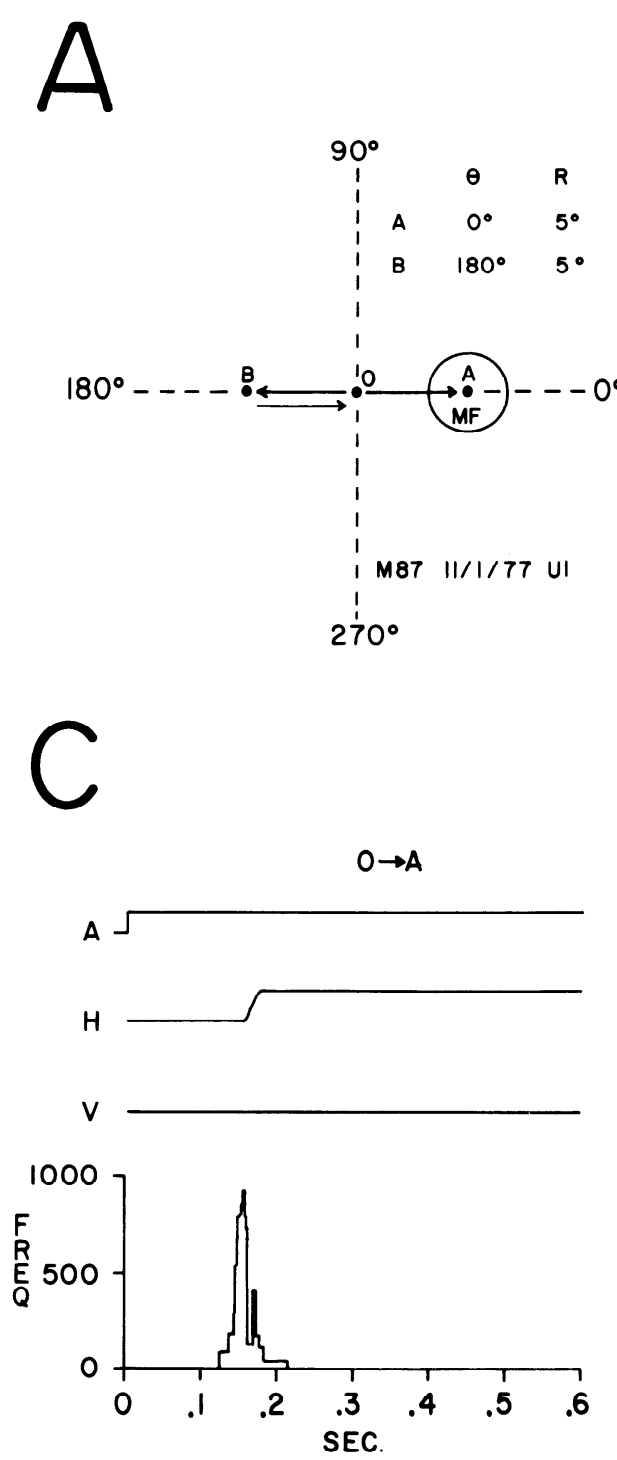

B
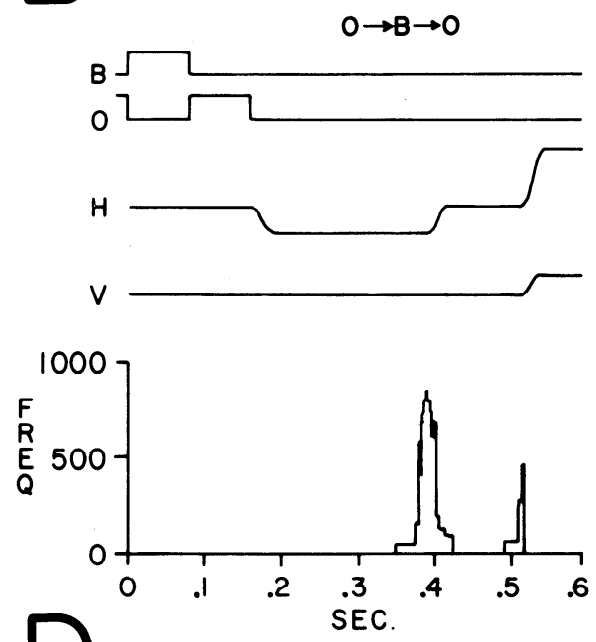

D
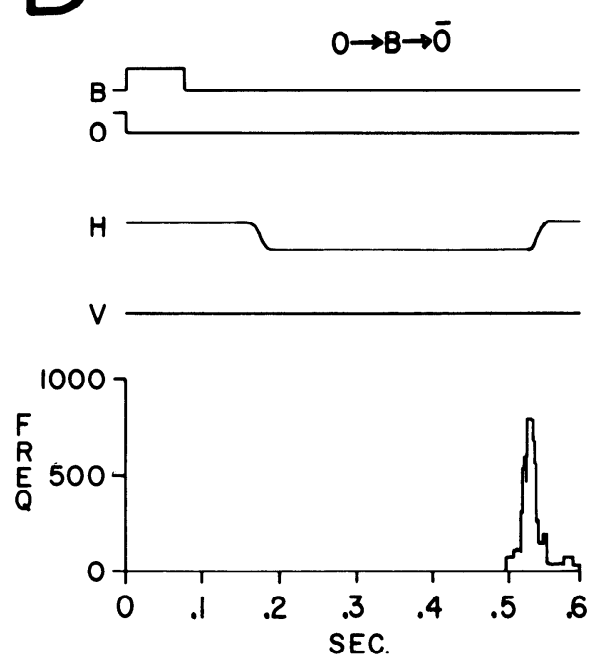

FIG. 3. Discharge patterns of a saccade-related cell. $A$ indicates that $5^{\circ}$ rightward saccades were within the movement field of this cell. $C$ shows the typical high-frequency burst of activity associated with a saccade within the movement field on an $\mathrm{O} \rightarrow \mathrm{A}$ trial. $\mathrm{B}$ shows the response of this cell on an $\mathrm{O} \rightarrow \mathrm{B} \rightarrow \mathrm{O}$ double-saccade trial. A brief target at $\mathrm{B}$ followed by a brief relighting of $\mathrm{O}$ elicited an $\mathrm{O} \rightarrow \mathrm{B}$ saccade followed by a return $\mathrm{B} \rightarrow \mathrm{O}$ saccade. The $\mathrm{B} \rightarrow \mathrm{O}$ saccade was almost identical to the $\mathrm{O} \rightarrow \mathrm{A}$ saccade and produced an equivalent neuronal discharge. Similarly, a brief target at B that elicited a saccade from $O$ to $\mathrm{B}$ and then back to $\mathrm{O}(D)$ produced an identical saccade-related discharge. A visual target never appeared in the right visual field on either of the trials shown in $B$ and $D$.

mediate layers of the SC slightly beneath the stratum opticum.

Figure 3 shows the response of a typical $\mathrm{SR}$ cell. Figure $3 A$ is a schematic representation of the target locations and movement field. On single-saccade $(\mathrm{O} \rightarrow \mathrm{A})$ trials, this cell showed a vigorous burst of activity beginning about $20 \mathrm{~ms}$ before a saccade to the middle of the movement field (Fig. $3 C$ ).
On double-saccade $(\mathrm{O} \rightarrow \mathrm{B} \rightarrow \mathrm{O}$ ) trials, if the $\mathrm{B} \rightarrow \mathrm{O}$ saccade was equivalent to the $\mathrm{O} \rightarrow \mathrm{A}$ saccade, a similar neural discharge was obtained (Fig. $3 B$ ). Figure $3 D$ shows a double-saccade $(\mathrm{O} \rightarrow \mathrm{B} \rightarrow \overline{\mathrm{O}})$ trial in which the target at $\mathrm{B}$ was a signal to make a saccade from $O$ to $B$ and then back to $O$. The $\mathrm{B} \rightarrow \mathrm{O}$ saccade was accompanied by a neural discharge equal to that seen in the 


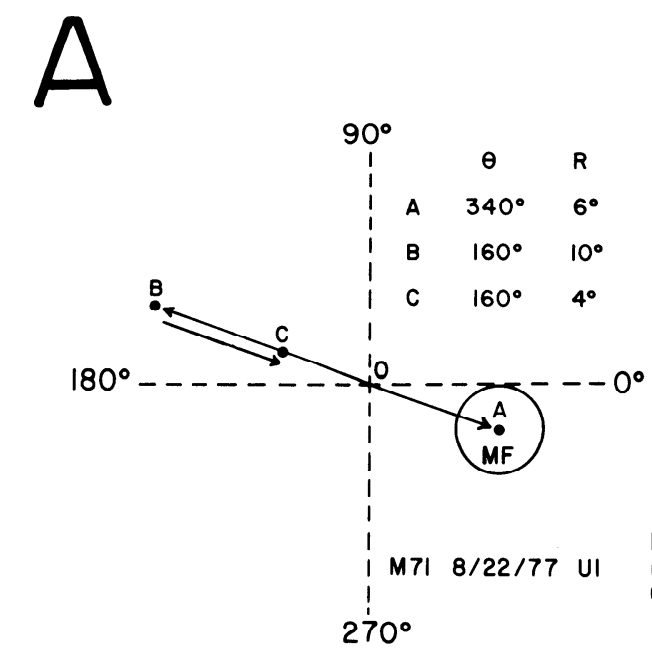

\section{B}
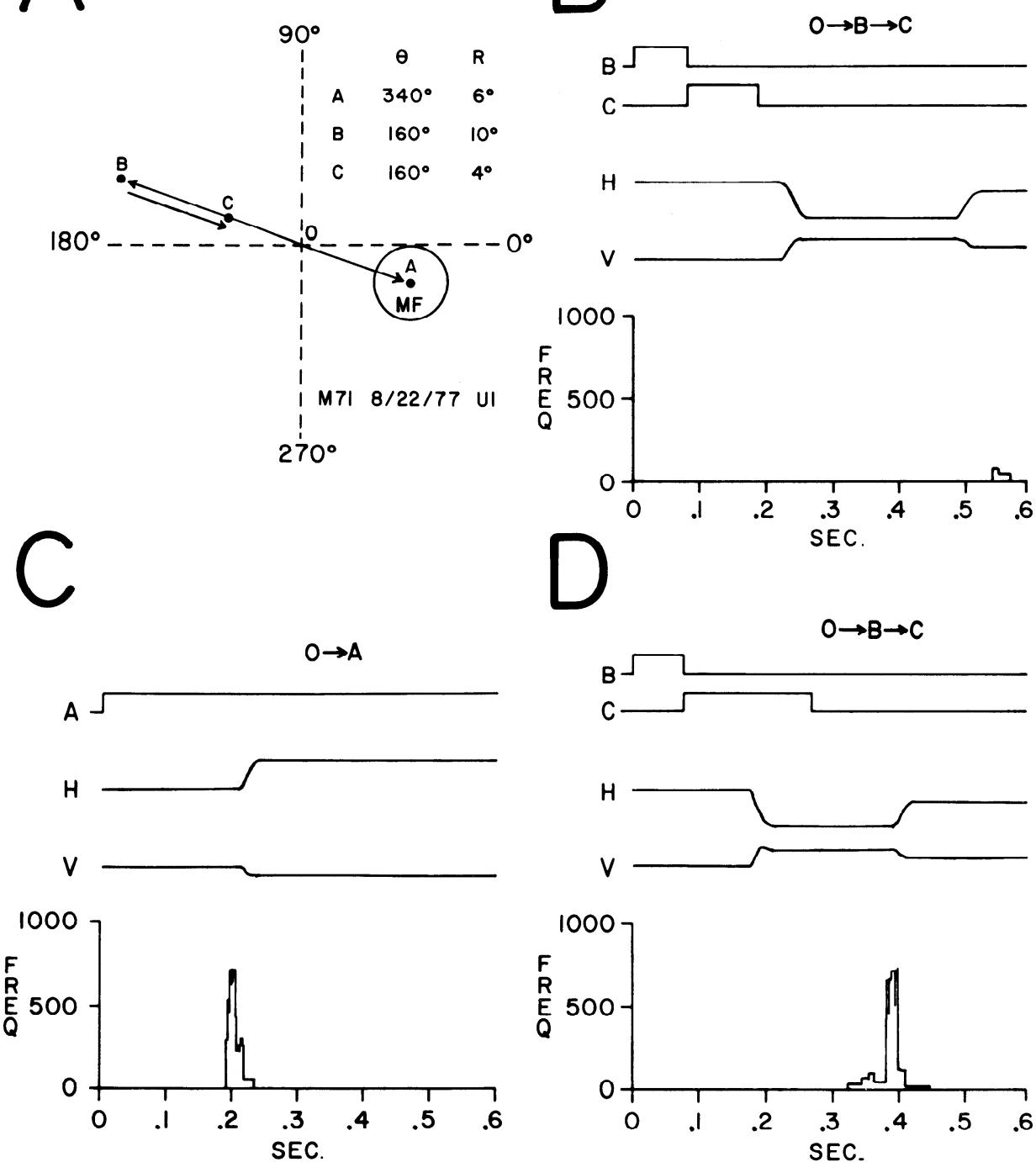

FIG. 4. Discharge patterns of a visually dependent saccade-related cell on single- and double-saccade trials. $A$ indicates that this cell's movement field included saccades of angle $\theta=340^{\circ}$ and amplitude $\mathrm{R}=6^{\circ}$. On $\mathrm{O} \rightarrow \mathrm{A}$ trials there was a vigorous burst of activity occurring just before the saccade to $\mathrm{A}(C)$. There was no evidence of a visual response. $B$ shows that on an $\mathrm{O} \rightarrow \mathrm{B} \rightarrow \mathrm{C}$ trial, in which a target never appeared in the left visual field, the saccade-related burst was absent. The $\mathrm{B} \rightarrow \mathrm{C}$ saccade was similar to the $\mathrm{O} \rightarrow \mathrm{A}$ saccade and was well within this cell's movement field. $D$ shows that the saccade-related burst was restored if target $C$ remained on until after the monkey looked to position B. The target at B was turned off more than $100 \mathrm{~ms}$ before the B $\rightarrow \mathrm{C}$ saccade, yet the saccade-related activity was similar to that seen on $\mathrm{O} \rightarrow \mathrm{A}$ trials.

$\mathrm{O} \rightarrow \mathrm{A}$ saccade. Similar results were obtained for this type cell on double-saccade $(\mathrm{O} \rightarrow \mathrm{B} \rightarrow \mathrm{C})$ trials in which the $\mathrm{B} \rightarrow \mathrm{C}$ saccades were equivalent to the $\mathrm{O} \rightarrow \mathrm{A}$ saccades.

The discharge of three of the 53 SR cells was dependent on an appropriate visual target. The response properties of one of these neurons are illustrated in Fig. 4. The location of this cell's movement field and the targets are shown in Fig. 4A. A vigorous burst of activity was observed just before a saccade within its movement field (Fig. 4C). The burst was always closely coupled to 
saccade onset. Extensive testing yielded no evidence that any component of the cell's discharge was related to stimulus onset. However, on double-saccade $(\mathrm{O} \rightarrow \mathrm{B} \rightarrow \mathrm{C})$ trials in which all targets were off before the monkey looked away from $\mathrm{O}$, the vigorous SR burst was absent, even though the $\mathrm{B} \rightarrow$ $C$ saccade was equivalent to the $\mathrm{O} \rightarrow \mathrm{A}$ saccade (Fig. $4 B$ ). Figure $4 D$ shows that the SR burst was contingent on a direct visual target for the saccade. On this $\mathrm{O} \rightarrow \mathrm{B} \rightarrow \mathrm{C}$ trial, the target at $\mathrm{C}$ was still present after the monkey looked to position B. A burst of activity was obtained that was comparable to that observed on $\mathrm{O} \rightarrow \mathrm{A}$ trials. The SR burst was not dependent on the target being on at the onset of the saccade. On the trial shown in Fig. $4 D$, target $\mathrm{C}$ was turned off about $140 \mathrm{~ms}$ before the saccade to $\mathrm{C}$. The discharge of these SR cells is clearly dependent on the presence of a visual stimulus that is the direct target of a saccade.

The discharge of 8 of the 53 SR cells was only partially dependent on a visual stimulus. Typical results for such a cell are shown in Fig. 5. Saccades in the cell's movement field were preceded by a burst of spikes on $\mathrm{O} \rightarrow$ A trials (Fig. 5A). These neurons did not appear to have a visual receptive field. Figure $5 C$ illustrates an $\mathrm{O} \rightarrow \mathrm{B} \rightarrow$ A control trial in which target $A$ (in the receptive field) appeared while the monkey looked at $\mathrm{O}$, but an $\mathrm{O} \rightarrow \mathrm{A}$ saccade was not required. Rather, the task requircd an $\mathrm{O} \rightarrow \mathrm{B}$ saccade followed by a $\mathrm{B} \rightarrow \mathrm{A}$ saccade. The absence of neuronal activity on this trial indicates that this cell was not visually activated by target A. Figure $5 B$ shows an $\mathrm{O} \rightarrow \mathrm{B} \rightarrow \mathrm{C}$ trial in which all targets were off before the $\mathrm{O} \rightarrow \mathrm{B}$ saccade. The $\mathrm{B} \rightarrow \mathrm{C}$ saccade was equivalent to the $\mathrm{O} \rightarrow \mathrm{A}$ saccade, but the spike burst accompanying the $\mathrm{B} \rightarrow \mathrm{C}$ saccade was much less vigorous than the burst accompanying the $\mathrm{O} \rightarrow \mathrm{A}$ saccade. However, if target $C$ remained on until the monkey looked to position $\mathrm{B}$, the discharge preceding the $\mathrm{B} \rightarrow \mathrm{C}$ saccade was comparable to the discharge seen on $\mathrm{O} \rightarrow A$ trials (Fig. 5D). The discharge of this cell was partially dependent on a direct visual target since it fired more vigorously when a saccade was made to such a target.

Of the 53 SR cells, 14 showed activity that sometimes preceded the saccade by several hundred milliseconds on double- saccade trials. The duration of this long-lead activity was roughly proportional to the delay between the signal to make a saccade and saccade onset. Figure $6 A$ shows a delayed-saccade $(\mathrm{O} \rightarrow \mathrm{O}+\mathrm{A} \rightarrow \mathrm{A})$ trial in which the monkey was required to maintain fixation of $\mathrm{O}$ for the first $300 \mathrm{~ms}$ after target A was turned on. A weak visual response followed by a brisk SR discharge was observed on this trial. On doublesaccade $(\mathrm{O} \rightarrow \mathrm{B} \rightarrow \overline{\mathrm{O}})$ trials in which the brief $(80 \mathrm{~ms})$ presentation of $B$ was a signal to make a saccade from $O$ to $B$ and then from $\mathrm{B}$ to $\mathrm{O}$, about $200 \mathrm{~ms}$ of low-level activity preceded the SR burst (Fig. 6B). A similar long-lead preburst discharge is shown (Fig. $6 D$ ) for another trial in which the $\mathrm{O} \rightarrow \mathrm{B}, \mathrm{B} \rightarrow \mathrm{O}$ intersaccadic interval was longer. On this trial, the preburst activation began about $300 \mathrm{~ms}$ before the $\mathrm{B} \rightarrow \mathrm{O}$ saccade. Figure $6 \mathrm{C}$ shows a missed double-saccade $(\mathrm{O} \rightarrow \mathrm{B} \rightarrow \overline{\mathrm{O}})$ trial, which indicates that the preburst activity was not due to the $\mathrm{O} \rightarrow \mathrm{B}$ saccade alone or to visual activation of the cell while the monkey looked at position B.

Some SR cells never showed significant preburst activity (see Fig. 3). Other cells often showed long-lead preburst activity on $\mathrm{O} \rightarrow \mathrm{B} \rightarrow \mathrm{C}$ trials and occasionally on an $\mathrm{O} \rightarrow \mathrm{A}$ trial. The preburst duration was roughly proportional to the delay between the signal to make a saccade and saccade onset, although the onset of the preburst activity was not tightly coupled to either the signal to make a saccade or to saccade onset. Since this pattern of activity tends to occur when saccades are delayed, the number of long-lead SR cells may be underestimated.

\section{Visual-motor cells}

Cells characterized as visual-motor had the following properties: 1 ) they produced a vigorous discharge in response to a stimulus in their receptive field, 2) they also showed a clear SR discharge, and 3 ) the visual response was eliminated and the SR response was retained on double-saccade trials in which no target appeared in the receptive field. Fifteen cells were placed in this category. Cells with these response properties were typically isolated beneath the visual cells and above SR cells. Although the presence of a visual and SR 

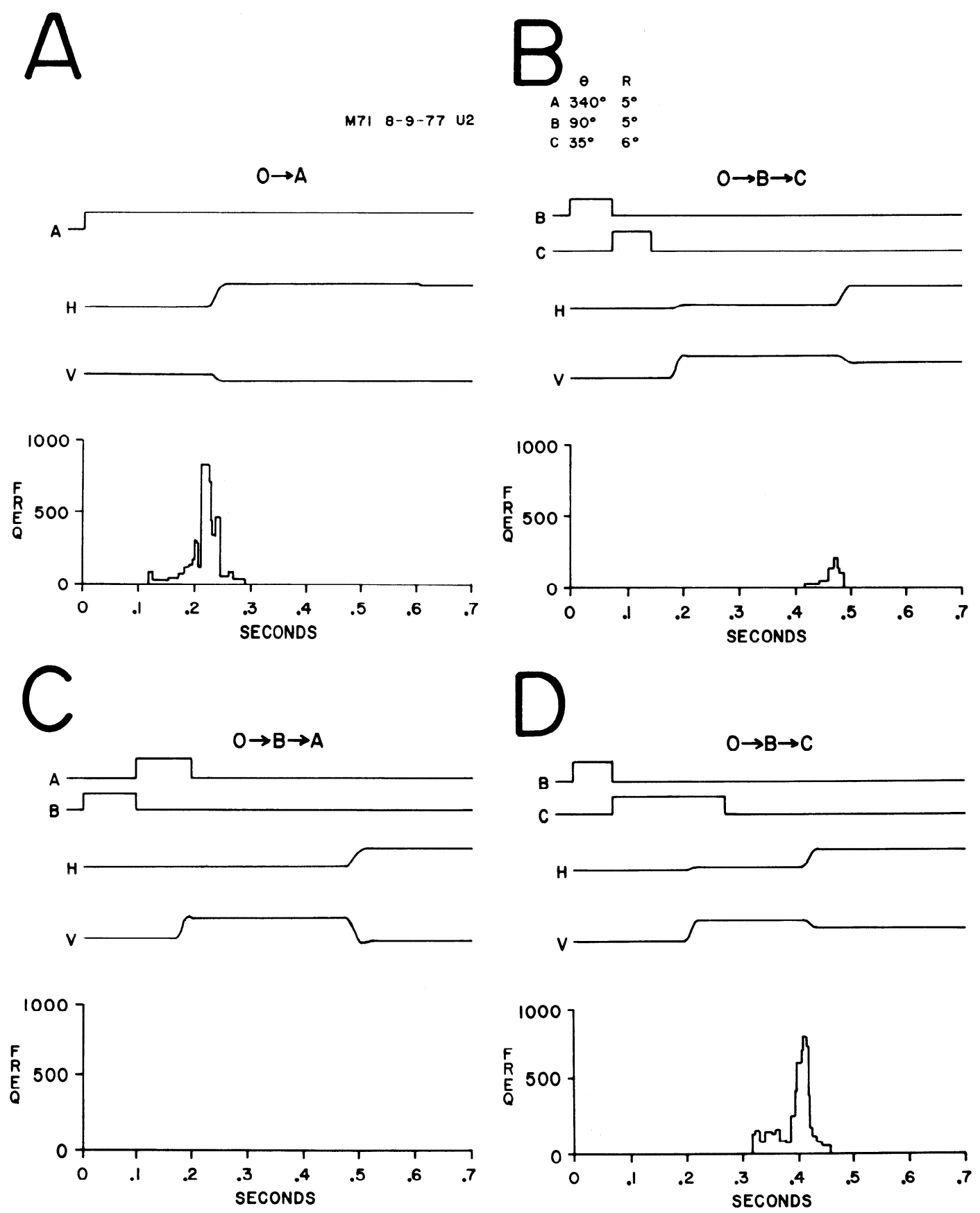

FIG. 5. Activation of a partially visually dependent saccade-related cell. $A$ shows an $\mathrm{O} \rightarrow \mathrm{A}$ single-saccade trial. This saccade to A was in the cell's movement field $\left(\theta=340^{\circ}, \mathrm{R}=5^{\circ}\right)$ and was preceded by a highfrequency burst of activity. $C$ shows that no activity was elicited during $\mathrm{O} \rightarrow \mathrm{B} \rightarrow \mathrm{A}$ trials in which target $\mathrm{A}$ appeared while the monkey looked at location $\mathrm{O}$. Thus, there was no visual response to a target at $\mathrm{A}$. $B$ shows that the response was attenuated if a target failed to appear in a location corresponding to the saccade vector. Note that all targets were off before the $\mathrm{O} \rightarrow \mathrm{B}$ saccade and that the $\mathrm{B} \rightarrow \mathrm{C}$ saccade was almost identical to the $\mathrm{O} \rightarrow \mathrm{A}$ saccade. $D$ shows that the absence of a direct-saccade target was responsible for the reduced neuronal response. If target $\mathrm{C}$ remained on after the monkey looked to position $\mathrm{B}$, a normal burst preceded the subsequent $\mathrm{B} \rightarrow \mathrm{C}$ saccade. 

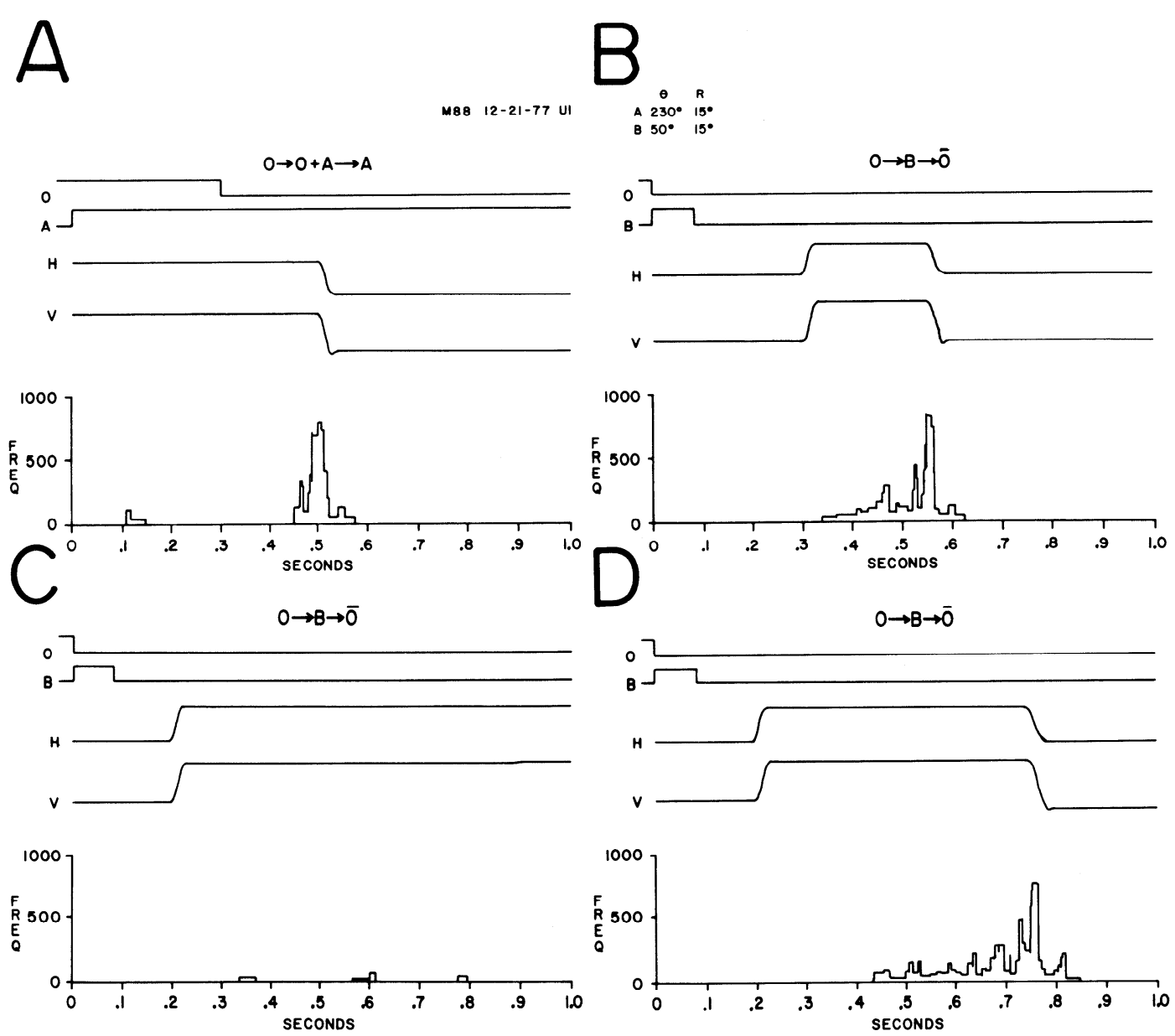

FIG. 6. Discharge patterns of a typical long-lead saccade-related neuron. $A$ shows a $\mathrm{O} \rightarrow \mathrm{O}+\mathrm{A} \rightarrow \mathrm{A}$ trial that required fixation of target $\mathrm{O}$ as long as it was present. A weak visual response (three spikes) occurred about $100 \mathrm{~ms}$ after target A onset. Target A remained on for $300 \mathrm{~ms}$ before target $\mathrm{O}$ was extinguished and a saccade to A occurred about $200 \mathrm{~ms}$ after the signal to move was given. A vigorous burst of activity, beginning no more than $50 \mathrm{~ms}$ before saccade onset, preceded the $\mathrm{O} \rightarrow$ A saccade. $B$ shows an $\mathrm{O} \rightarrow \mathrm{B} \rightarrow \overline{\mathrm{O}}$ trial in which an 80 -ms target at $\mathrm{B}$ was a signal to look to $\mathrm{B}$ and then back to $\mathrm{O}$. The $\mathrm{B} \rightarrow \mathrm{O}$ saccade was preceded by nearly $200 \mathrm{~ms}$ of low-level activity before the saccade-related burst. The $\mathrm{O} \rightarrow \mathrm{A}$ saccade shown in $A$ was comparable to this $\mathrm{B} \rightarrow \mathrm{O}$ saccade but was not accompanied by long-lead activation. $C$ shows that the low-level activity was not due to the $\mathrm{O}$ to $\mathrm{B}$ saccade or to any visual factors that might have been present while the monkey was looking at location $B$. $D$ shows another $\mathrm{O} \rightarrow \mathrm{B} \rightarrow \mathrm{O}$ trial in which the return saccade was delayed and was somewhat less accurate. Examination of $B$ and $D$ reveals that the onset of the long-lead activation was not tightly linked to either stimulus or response events.

response makes further categorization difficult, five of these cells appeared to show long-lead SR activation on some trials. Two visual-motor cells appeared to have a motor response that was dependent, in part, on the occurrence of a visual stimulus in the receptive field.

\section{Quasi-visual cells}

Cells placed in this category displayed the following properties: $l$ ) on single- saccade trials, these neurons produced a sustained response to the presence of a stimulus in their receptive field; 2 ) alterations in spike activity associated with saccade onset were not observed on singlesaccade trials; 3 ) unlike visual cells, these neurons discharged on double-saccade trials even though a visual stimulus failed to appear in the receptive field; and 4) the discharge that occurred on double-saccade trials was not tightly linked to stimulus or 

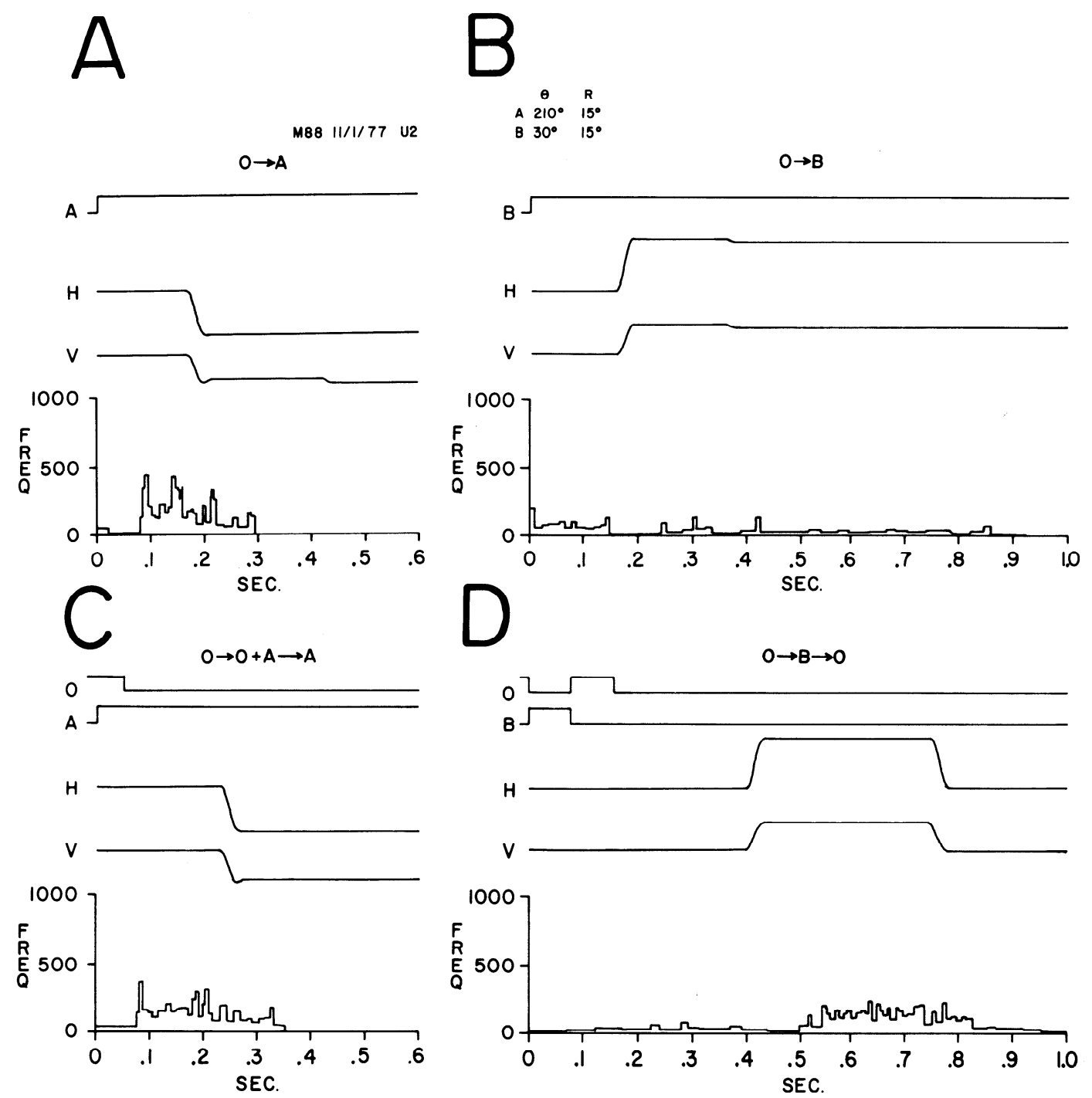

FIG. 7. Discharge patterns of a quasi-visual (QV) cell. $A$ shows the response of this cell to the appearance of a target in its receptive field at $\mathrm{A}\left(\theta=210^{\circ}, \mathrm{R}=15^{\circ}\right) . C$ shows an $\mathrm{O} \rightarrow \mathrm{O}+\mathrm{A} \rightarrow \mathrm{A}$ saccade trial in which the saccade was delayed because of the continued appearance of target $O$. On both trials, the onset of neuronal activity was closely linked to stimulus onset and there were no obvious saccade-associated changes in spike rate. $D$ shows an $\mathrm{O} \rightarrow \mathrm{B} \rightarrow \mathrm{O}$ trial in which all targets were off before the monkey looked from the fixation point. The $\mathrm{B} \rightarrow \mathrm{O}$ saccade was similar to the $\mathrm{O} \rightarrow \mathrm{A}$ saccades in $A$ and $C$. Shortly after the monkey looked to location $\mathrm{B}$, the cell began to fire and continued through the return saccade. $B$ shows that the activation of this cell was not due to the $\mathrm{O} \rightarrow \mathrm{B}$ saccade or to visual activation of the cell while the eyes were directed at $\mathrm{B}$.

response events. Twenty-three cells were observed that showed these properties. These were not the most superficial cells encountered, but tended to be above most SR cells. However, some quasi-visual (QV) neurons were isolated at the level of or slightly below the first SR cells.

On single-saccade trials, QV neurons appear to be visual neurons producing a sustained response to stimuli in the receptive field. Figure $7 A$ shows the typical response of a QV cell on $\mathrm{O} \rightarrow$ A trials. An abrupt increase in activity was observed about $70 \mathrm{~ms}$ after the onset of a visual target in the receptive field. The increased discharge frequency continued until shortly after the saccade to acquire target A. Observations of many trials with varying 

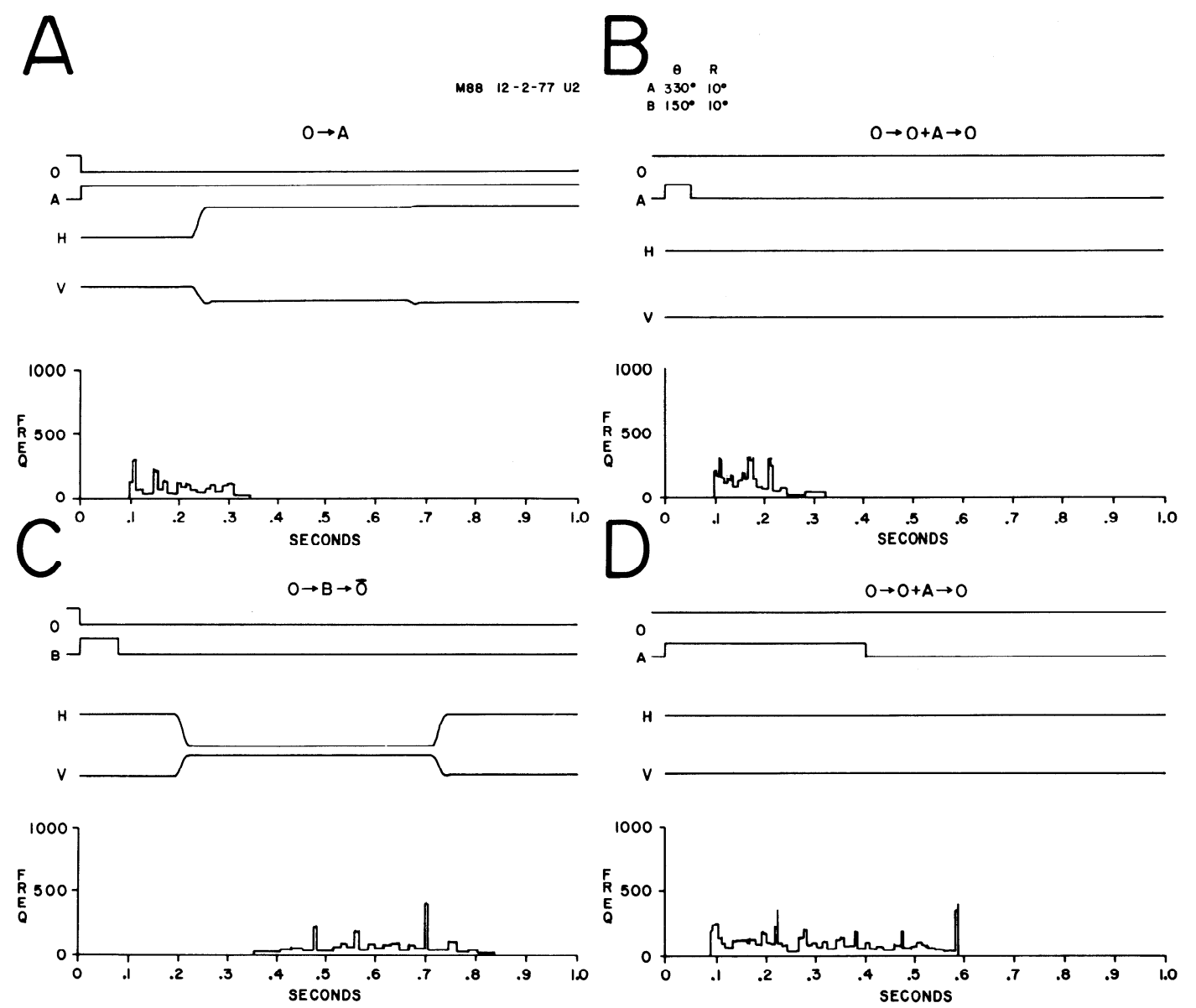

FIG. 8. Discharge of a QV cell on visual-probe trials. $A$ shows a neuronal response on a $\mathrm{O} \rightarrow \mathrm{A}$ saccade trial to a visual stimulus in the cell's receptive field at location $\mathrm{A}\left(\theta=330^{\circ}, \mathrm{R}=10^{\circ}\right)$. $C$ shows that an $\mathrm{O} \rightarrow \mathrm{B} \rightarrow \overline{\mathrm{O}}$ trial produced the response typical of a QV cell. $B$ and $D$ show $\mathrm{O} \rightarrow \mathrm{O}+\mathrm{A} \rightarrow \mathrm{O}$ visual-probe trials using short $(40 \mathrm{~ms})$ and longer $(400 \mathrm{~ms})$ durations of the target in the receptive field. The duration of the neuronal response reflects stimulus duration.

saccadic latencies clearly indicated that the discharge was tightly coupled to stimulus onset rather than saccade onset. On delayedsaccade $(\mathrm{O} \rightarrow \mathrm{O}+\mathrm{A} \rightarrow \mathrm{A})$ trials, the increase in spike activity was closely associated with target onset, not saccade onset, and the activity continued until just after the $\mathrm{O} \rightarrow \mathrm{A}$ saccade (Fig. 7C). Since on single-saccade and delayed-saccade trials the saccade to A removed target $A$ from the receptive field, these neurons appeared to respond in a sustained manner to a visual stimulus.

Figure 8 illustrates the discharge of $\mathrm{QV}$ cells on visual-probe $(\mathrm{O} \rightarrow \mathrm{O}+\mathrm{A} \rightarrow \mathrm{O})$ trials with a brief $(50 \mathrm{~ms})$ target duration (Fig. $8 B$ ) and with a longer (400 ms) duration
(Fig. 8D). On both trials, the cell started firing about $80-90 \mathrm{~ms}$ after target $A$ onset and ceased firing about $200 \mathrm{~ms}$ after target offset. Thus, the duration of the spike discharge was roughly proportional to stimulus duration. Note that on visualprobe trials, QV cells discharged in response to visual stimuli in their receptive field, even if a saccade to acquire the stimulus did not occur. The sustained response to stimuli in the receptive field typical of QV cell activity on single-saccade trials is shown in Fig. $8 A$. The discharge occurring on double-saccade $(\mathrm{O} \rightarrow \mathrm{B} \rightarrow \overline{\mathrm{O}})$ trials, an identifying feature of QV cells, is illustrated in Fig. $8 C$.

Unlike visual cells, QV cells discharge 
on double-saccade trials even though a visual stimulus does not appear in the receptive field. Figure $7 D$ shows the response of a QV cell on a $\mathrm{O} \rightarrow \mathrm{B} \rightarrow \mathrm{O}$ trial in which the $\mathrm{B} \rightarrow \mathrm{O}$ saccade was equivalent to the $\mathrm{O} \rightarrow \mathrm{A}$ saccade. Targets $\mathrm{B}$ and $\mathrm{O}$ were at least 25 and $10^{\circ}$, respectively, from the edge of the visual receptive field. The durations of the targets at $\mathrm{B}$ and $\mathrm{O}$ were so brief $(80 \mathrm{~ms}$ each) that all targets were off before the onset of the $\mathrm{O} \rightarrow \mathrm{B}$ saccade. Even though a target did not appear in the cell's receptive field, the cell began to discharge just after the monkey looked at position $\mathrm{B}$ and continued through the return saccade to $\mathrm{O}$. The neural response on $\mathrm{O} \rightarrow$ $\mathrm{B} \rightarrow \mathrm{O}$ trials was not an artifact caused by oscilloscope persistence or by stray images being moved into the receptive field following the $\mathrm{O} \rightarrow \mathrm{B}$ saccade. This is shown by Fig. $7 B$, which demonstrates that no activation of this cell occurred on $\mathrm{O} \rightarrow \mathrm{B}$ saccade trials. The initial $\mathrm{O} \rightarrow \mathrm{B}$ saccades are virtually identical in Fig. $7 B$ and $D$. A stray image (e.g., a reflection or part of the apparatus) being moved into the receptive field would activate the cell on an $\mathrm{O} \rightarrow \mathrm{B}$ trial as on an $\mathrm{O} \rightarrow \mathrm{B} \rightarrow \mathrm{O}$ trial. Furthermore, the response on the $\mathrm{O} \rightarrow \mathrm{B} \rightarrow \mathrm{O}$ trial could not be due to oscilloscope persistence since the fixation point at $\mathrm{O}$ was turned off $250 \mathrm{~ms}$ before the monkey looked to $\mathrm{B}$ in the $\mathrm{O} \rightarrow \mathrm{B} \rightarrow \mathrm{O}$ trial (Fig. $7 D$ ) and only $170 \mathrm{~ms}$ before the monkey looked to position $B$ in the $\mathrm{O} \rightarrow \mathrm{B}$ trial (Fig. $7 B$ ). Additional arguments that the discharge of QV cells on double-saccade trials cannot be attributed to oscilloscope persistence are given in the DISCUSSION.

The onset of the QV response occurring on double-saccade trials is not tightly coupled to either the occurrence of visual stimuli or to saccade onset. Note, for example, in Fig. $8 C$ that the QV cell discharge began approximately $250 \mathrm{~ms}$ after the offset of all visual stimuli (see also Figs. $7 D$ and $9 C$ ). The discharge of QV cells is not tightly coupled to saccade onset since vigorous discharges occur in the absence of saccades (Fig. $8 B$ and $D$ ). A further dissociation of QV cell activity from saccades to acquire a target is illustrated in Fig. 9. Figure $9 A$ and $C$ shows that this cell, like other QV cells, discharges on both single- and double-saccade trials. There was no significant change in neuronal activity on the $\mathrm{O} \rightarrow \mathrm{B}$ control trial. The probability of a saccade to position A was manipulated by varying the duration of targets on $\mathrm{O} \rightarrow \mathrm{A} \rightarrow \mathrm{O}$ trials. At relatively long durations of $A(80 \mathrm{~ms})$, the monkey usually looked to $\mathrm{A}$ and then back to $\mathrm{O}$. With very short durations of $\Lambda(40-60$ $\mathrm{ms})$ and longer durations of $\mathrm{O}(80 \mathrm{~ms})$, the monkey looked to A on some trials and continued to fixate $\mathrm{O}$ on other trials. When short durations of target $A$ produced a saccade to $A$, the onset of these saccades was usually delayed $(400-700 \mathrm{~ms})$ when compared to normal $\mathrm{O} \rightarrow$ A saccade latencies (150-200 ms). Figure $9 B$ shows a trial in which a $50 \mathrm{~ms}$ duration of $A$ and an $80 \mathrm{~ms}$ relighting of $\mathrm{O}$ resulted in a saccade from $\mathrm{O}$ to A with a long latency $(450 \mathrm{~ms})$. This cell began to fire about $90 \mathrm{~ms}$ after the onset of target $A$ and continued to discharge until sometime after the saccade to A. Figure $9 D$ shows a similar $\mathrm{O} \rightarrow \mathrm{A} \rightarrow \mathrm{O}$ trial in which a $40 \mathrm{~ms}$ duration of $\mathrm{A}$ did not result in a saccade to A. Again, this cell began to discharge about 90-100 ms after target A was turned on and continued to fire for about $800 \mathrm{~ms}$. The cell's activity returned to baseline level about the time the monkey looked away from position $O$ (but not to target A). Similar results were obtained with at least eight other QV cells. A sustained response to a brief stimulus was often seen on trials in which the stimulus timing resulted in a saccade about half of the time. The sustained response can be dissociated from a saccade to the target location.

From these results it appears that the discharge of QV cells can be initiated or maintained by events that indicate that a saccade with a particular direction and amplitude is appropriate. Thus, QV cell activity is initiated by the onset of target $\mathrm{A}$ on single-saccade trials (Figs. $7 A, 7 C, 8 A$, $9 A$ ). On double-saccade trials, the particular saccade becomes appropriate only after the first $(\mathrm{O} \rightarrow \mathrm{B})$ saccade and $\mathrm{QV}$ cell activity begins after this first saccade (Figs. $7 D, 8 C, 9 C$ ). Once initiated, the discharge of QV neurons continues until the saccade occurs (e.g., Figs. $7 A, 7 C, 7 D, 8 A, 8 C, 9 A$, $9 B, 9 C)$ or until the saccade is canceled (Figs. $8 B, 8 D, 9 D$ ).

The indication that the discharge of QV cells is initiated when a saccade is appropriate even if it is not executed (Fig. 9D) 

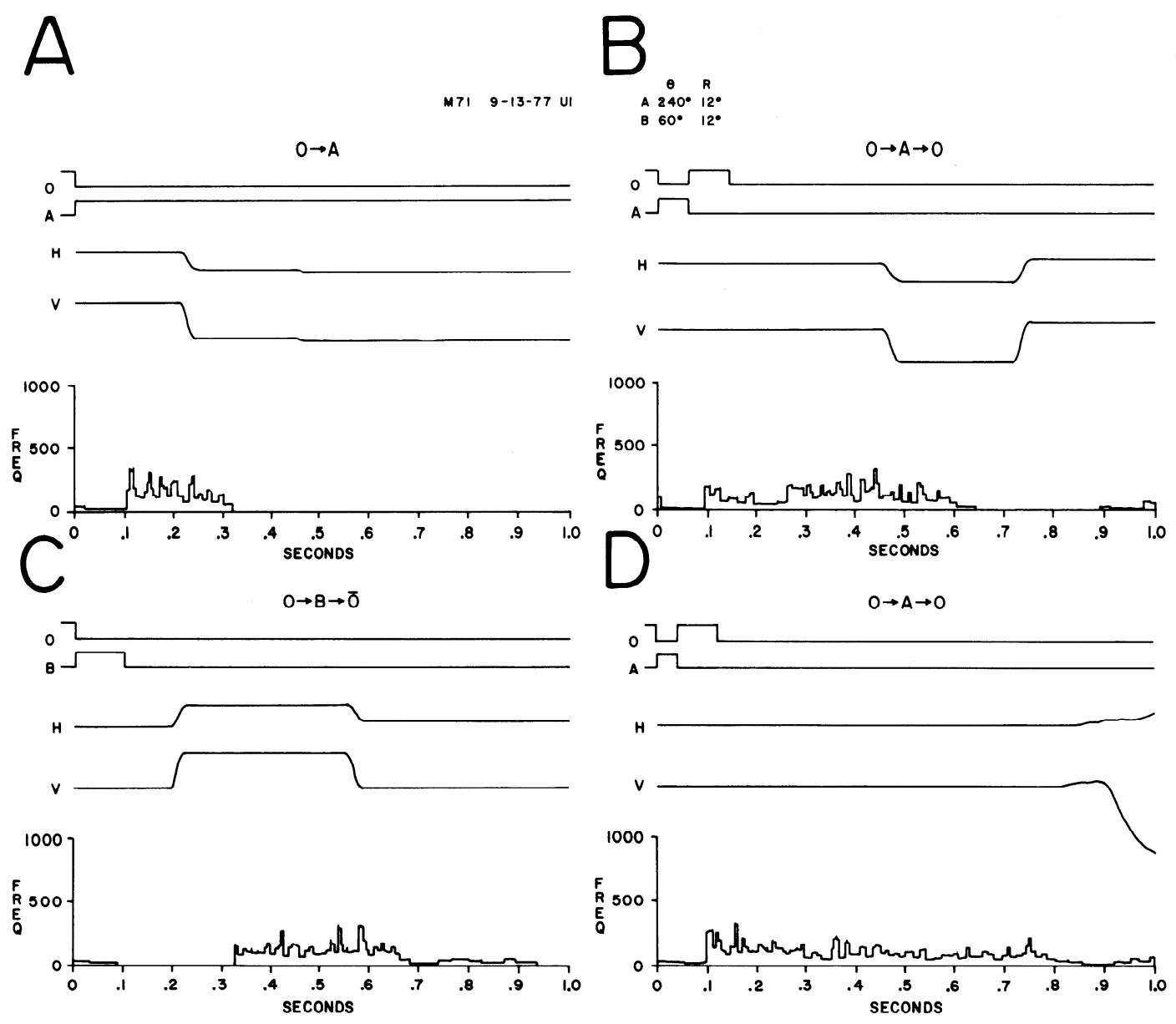

FIG. 9. Long-duration activation of a QV cell. $A$ shows the discharge pattern typically observed on $\mathrm{O} \rightarrow \mathrm{A}$ trials. The visual stimulus was in the cell's receptive field for about $220 \mathrm{~ms}$ and the duration of the neuronal discharge was about $210 \mathrm{~ms}$. Discharge patterns typical of $\mathrm{O} \rightarrow \mathrm{B} \rightarrow \overline{\mathrm{O}}$ trials are shown in $C . B$ and $D$ show the discharge of this cell on $\mathrm{O} \rightarrow \mathrm{A} \rightarrow \mathrm{O}$ trials in which a brief stimulus at $\mathrm{A}$ followed by a brief relighting of $\mathrm{O}$ sometimes produced a saccade to $\mathrm{A}$ and sometimes did not. In $B$ a saccade occurred after an unusually long latency (450 ms). The cell began to fire $90 \mathrm{~ms}$ after target $A$ appeared and continued to fire until the saccade to A. $D$ shows a similar trial in which no saccade to A occurred. Again, the cell began to fire when target A appeared and continued for about $700 \mathrm{~ms}$ when the monkey looked away from location O. Sustained activation of QV cells does not depend on either the presence of a visual stimulus in the receptive field or the act of making a saccade to it.

raises the possibility that QV cells may not actually be visually responsive. Although QV cells discharge with a nearly constant latency to the onset of a target in the receptive field on $\mathrm{O} \rightarrow \mathrm{A}$ and delayed-saccade $(\mathrm{O} \rightarrow \mathrm{O}+\mathrm{A} \rightarrow \mathrm{A})$ trials, this response could be an indication that a particular saccade is appropriate rather than be a true visual response. If this were the case, then the visual-probe $(\mathrm{O} \rightarrow \mathrm{O}+\mathrm{A} \rightarrow \mathrm{O})$ trial would not be an adequate procedure for assessing visual responsiveness. Since delayed-saccade and visual-probe trials are identical until either the fixation $(\mathrm{O})$ or peripheral (A) target is extinguished, a visual-probe trial might be interpreted as a delayed-saccade trial by the monkey. If QV cells can be activated when a saccade becomes appropriate (regardless of whether the saccade occurs), then the response of QV cells on visual-probe trials may not represent a visual response.

In order to determine if $\mathrm{QV}$ cells are visually responsive, four monkeys were tested on $\mathrm{O} \rightarrow \mathrm{B} \rightarrow \mathrm{A}$ double-saccade trials. These trials were identical to $\mathrm{O} \rightarrow$ $\mathrm{B} \rightarrow \mathrm{C}$ double-saccade trials except that the second target (A) was within the receptive 


\section{A}

B

$\theta \mathrm{R}$

A $240^{\circ} 12^{\circ}$

M71 9-13-77 UI

B $315^{\circ} 10^{\circ}$

C $195^{\circ} 14^{\circ}$
$O \rightarrow B \rightarrow A$
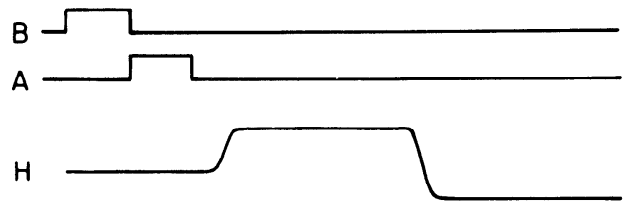

v
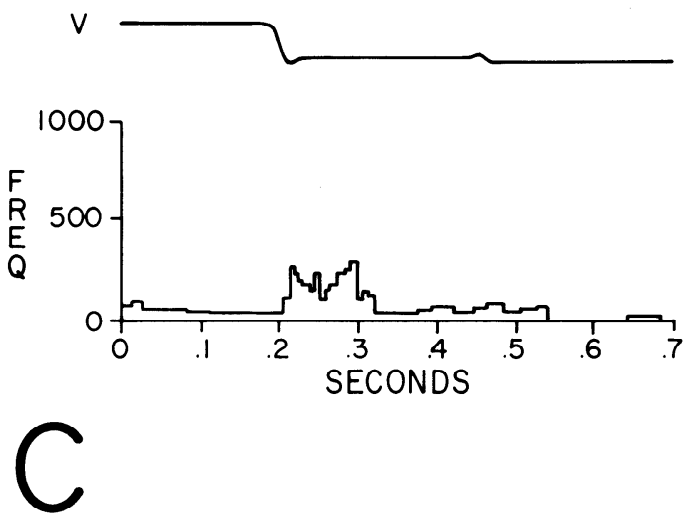

$O \rightarrow B$

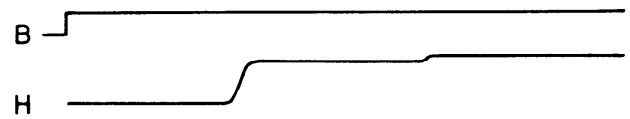

v

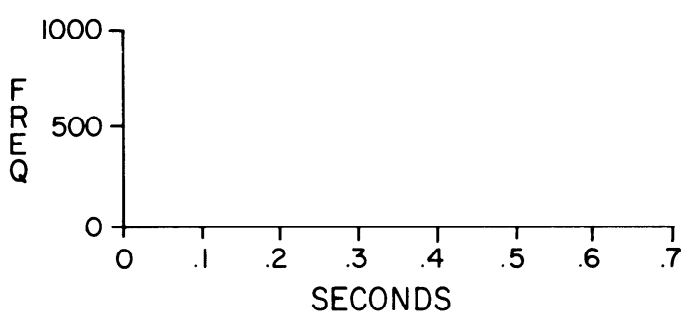

$O \rightarrow B \rightarrow A$

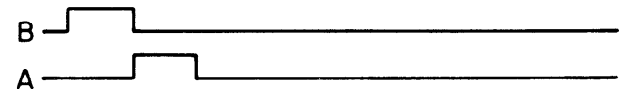

H

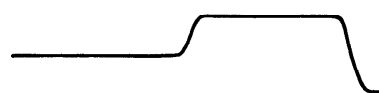

v

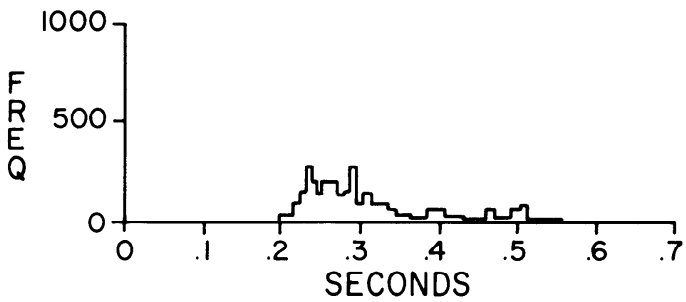

D

$0 \rightarrow C$

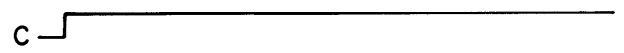

H

V
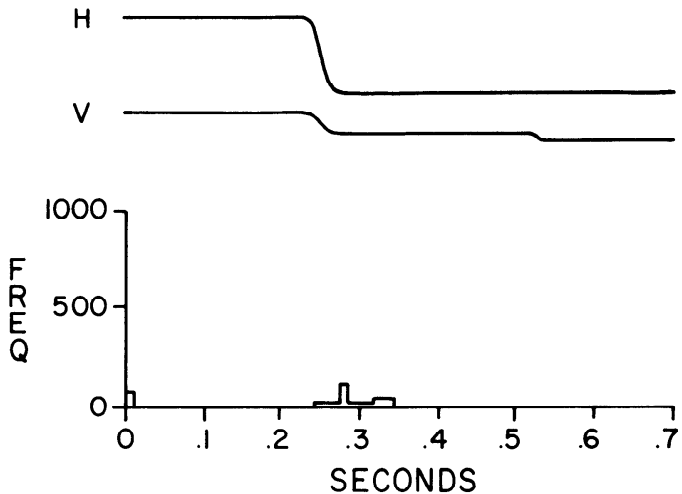

FIG. 10. Responses of a QV cell to a visual stimulus presented in the receptive field just before a saccade to another location. $A$ and $B$ show $\mathrm{QV}$ cell activity on $\mathrm{O} \rightarrow \mathrm{B} \rightarrow \mathrm{A}$ trials in which the stimulus at location $\mathrm{A}$ is in the cell's receptive field when the monkey is looking at target $O$. Target $B$ is not in the cell's receptive field when the monkey is looking at either $\mathrm{O}$ or $\mathrm{A}$. (Target $\mathrm{A}, \theta=240^{\circ}, \mathrm{R}=12^{\circ}$; target $\mathrm{B}, \theta=315^{\circ}, \mathrm{R}=10^{\circ}$.) In $A$ and $B$, target B is flashed for $80 \mathrm{~ms}$ followed by target A for $80 \mathrm{~ms}$. As with other double-saccade trials, the monkey must look to the locations of the flashed stimuli in the correct sequence to obtain a reward. Thus, target A is flashed in the cell's receptive field just before a saccade to $B$ is made. If $Q V$ cells indeed have a visual response, then they should discharge to the stimulus in the receptive ficld regardless of the vector of the impending saccade. If the QV response is instead related to the vector of the impending saccade and only appears to be visual, then no response should occur. $A$ and $B$ indicate that this QV cell does have a visual response. $C$ is a control trial, which shows that target B is not within the cell's receptive field. $D$ shows that a saccade similar to the saccade from B to A is not preceded by any neuronal activity. 
field of the cell under study. The effect of this trial is to briefly present a target in the cell's receptive field (at $A$ ) just before the monkey looks to another target (at B). If QV cells are visually responsive, then the appearance of a stimulus in the receptive field should elicit a discharge even though the monkey will be making a saccade to another location. If QV cell activity represents an "expectation" of making a saccade of a particular vector, then no discharge should occur since an irrelevant saccade will be executed.

Figure 10 shows the response of a QV cell on two $\mathrm{O} \rightarrow \mathrm{B} \rightarrow \mathrm{A}$ visual-test trials. The cell in Fig. 10 is the same QV cell as shown in Fig. 9. Figure $10 A$ and $B$ shows the result of 80 -ms presentations of a stimulus in the cell's receptive field (at A) just prior to a saccade to $B$. A vigorous burst of activity occurs about $110-120 \mathrm{~ms}$ after the onset of the stimulus at $\Lambda$, even though a saccade to $B$ occurs. This result may be compared to trials shown in Fig. 9A, B, and $C$. Figure $10 C$ shows that neither the appearance of a target at $B$ nor a saccade to $B$ is sufficient to activate this cell. Similarly, Fig. 10D demonstrates that a saccade similar in direction and amplitude to the $\mathrm{B} \rightarrow$ A saccade is followed by a weak discharge of only four spikes. Similar results were obtained for all of the other nine QV cells that were tested with this trial type.
These results suggest that QV cells are indeed visually responsive and that an impending saccade of a certain vector is not necessary to produce activation.

The suggestion that QV cell activity may be maintained by events signaling the appropriateness of a saccade with a particular vector is supported by a chance observation made during these experiments. Figure 11 shows the activity of a QV cell (the same cell shown in Fig. 7) on a visual-probe $(\mathrm{O} \rightarrow$ $\mathrm{O}+\mathrm{A} \rightarrow \mathrm{O}$ ) trial. On this trial, a target was presented briefly $(40 \mathrm{~ms})$ in the cell's receptive field. The monkey was required to maintain fixation of $\mathrm{O}$ for the duration of the trial. On the trial shown, the monkey held fixation of $\mathrm{O}$ until the end of the trial (marked by the arrow just after $1.0 \mathrm{~s}$ ) and then made a saccade to the approximate location of target A about $700 \mathrm{~ms}$ later. Vigorous neuronal activity began $70 \mathrm{~ms}$ after the onset of the brief target at $A$ and continued at a high level until the end of the trial at $1 \mathrm{~s}$. The cell continued to fire at a lower rate until just after the saccade to the approximate position of $\mathrm{A}$.

\section{DISCUSSION}

On double-saccade trials, monkeys were required to look to the location of a visual target presented briefly during fixation even though another saccade intervened. An

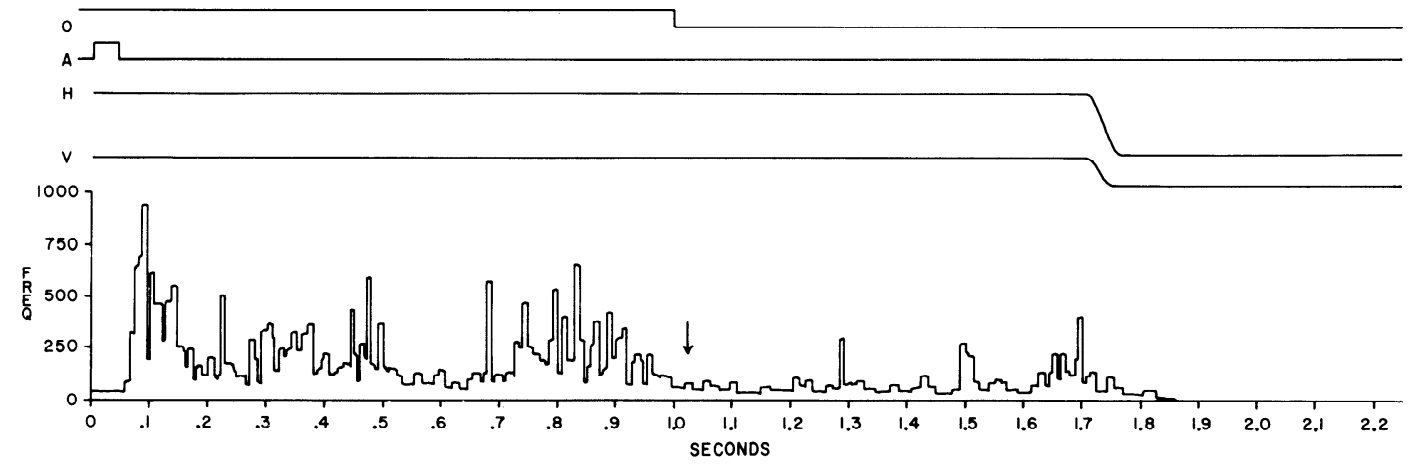

FIG. 11. A chance observation of a saccade with a long latency. Figure 10 shows an $\mathrm{O} \rightarrow \mathrm{O}+\mathrm{A} \rightarrow \mathrm{O}$ visualprobe trial that occurred early in training. The monkey had performed many thousands of trials that required a saccade to a visual target and only a few trials that required continued fixation of the initial target while another target was flashed. On this trial the monkey held center fixation for over $1 \mathrm{~s}$ while a brief (40 ms) target appeared. About 700 ms.after the reinforcement was delivered (arrow), the monkey looked to the approximate location at which target $\mathrm{A}$ had appeared. This figure shows the response of a QV cell (the same cell as in Fig. 7) on this trial. The brief appearance of target $\mathrm{A}$ in the cell's receptive field produced a sustained response. Although the cell's discharge rate slowed somewhat after the reinforcement was delivered, the activity continued until the saccade to the approximate location of $\mathrm{A}$. 
important feature of this task is that the retinal error signal alone cannot be used to program a saccade to acquire the target. Visual stimuli activating almost any region of the retina can be used to trigger a saccade with a particular direction and amplitude. Thus, the site of retinal stimulation is dissociated from the metrics of the saccade that the stimulation elicits. The most important characteristics of SC cells revealed by these manipulations are discussed below. The relation of the properties of these cells to previous descriptions of SC activity is examined. Finally, the results of the present study are discussed in terms of current models of the saccadic system.

\section{Visual cells}

Visual cells respond only to the appearance of a visual stimulus in their receptive field, are not activated by saccades in the absence of an appropriate visual stimulus, and thus appear to reflect retinal stimulation faithfully. The activity of these neurons signals the occurrence of a visual stimulus whether or not the stimulus is selected for foveal viewing. Schiller et al. (17) reported that the most superficial cells encountered in the monkey SC were reliably driven by visual stimuli, were difficult to isolate, and had relatively small receptive fields. Most of the cells classified as visual in the present study match this description well. Furthermore, Schiller et al. (17) reported that the superficial visual cells are generally unaffected by cooling of cortical area 17 and concluded that these cells were probably recipients of direct retinal projections. The properties of visual cells are those that would be expected of cells driven by direct retinal inputs. However, this hypothesis was not directly tested.

\section{Saccade-related cells}

Saccade-related cells discharge just prior to saccades within their movement field. Most SR cells also discharge on doublesaccade trials. Thus, the presence of a visual stimulus as a direct saccade target had no effect on either the vigor or probability of an SR discharge. This finding is consistent with previous reports that some SR cells discharge before spontaneous saccades in the dark $(11,15,16,21,24)$, to the fast phase of caloric nystagmus $(16,24)$, and to operantly elicited saccades in the absence of a visual saccade target (11).

A small proportion (11 of 53) of SR cells is either partially or completely dependent on a direct saccade target to produce an SR discharge. Mohler and Wurtz (11) were the first to describe visually triggered motor (VTM) cells in the monkey SC. According to their report, VTM cells have both a visual receptive field and produce an SR discharge when saccades are made to a visual target. These cells are silent during similar spontaneous saccades in the dark or light. Some VTM cells have a reduced discharge before operantly elicited saccades in the absence of a visual saccade target.

The results of the present study confirm and extend the observations of Mohler and Wurtz (11). Visually dependent SR cells with visual fields were encountered in the present study. In addition, visually dependent cells that had no visual response were isolated, thus indicating that the property of visual dependence is not restricted to cells with receptive fields. Furthermore, even a brief appearance of a direct-saccade target was sufficient to enable a visually dependent SR cell to fire. Thus, a visually dependent SR cell does not require that a visual stimulus be present at the initiation of the saccade; it is necessary only that the target has recently appeared in an area of the visual field that corresponds to the movement field of the cell.

\section{Long-lead SR cells}

Fourteen of the 53 SR cells showed clear evidence of sustained activity that could precede a saccade by several hundred milliseconds. Long-lead activity was most often seen on single-saccade trials with unusually delayed saccade onsets or prior to the second saccade of a double-saccade trial. This long-lead activity is clearly not visual (see Fig. $6 C^{\prime}$ and $D$ ).

Mohler and Wurtz (11) observed 15 intermediate layer cells with SR discharges that were only loosely coupled to saccades. The discharge was not visual, yet could precede the saccade by several hundred milliseconds and occurred even if there was no saccade. If the monkey was allowed to anticipate target location and time of onset, the discharge could even precede the saccade 
trigger signal. Using $\mathrm{O} \rightarrow \mathrm{A} \rightarrow \mathrm{O}$ trials in which the duration of the stimulus at $A$ could be varied, Sparks (19) was able to manipulate the probability of eliciting a saccade to A. One class of SC cells generated a high-frequency pulse of activity that was nearly perfectly correlated with the occurrence of a saccade. In addition to this tightly coupled pulsatile activity, some SR cells displayed a prepulse discharge of lower frequency that sometimes preceded the pulse by more than $100 \mathrm{~ms}$. This prepulse activity, seemingly identical to the long-lead activation observed in the present study, was always less vigorous than the SR burst, and was often observed even when no saccade occurred.

The experiments of Mohler and Wurtz (11), Sparks (19), and the present study indicate that there is a component of the discharge of SR cells that, while not visual, is only very loosely related to the occurrence of a saccade of a certain vector. This long-lead activity is dissociable from the SR burst of activity shown by many of these cells.

\section{Quasi-visual cells}

Quasi-visual cells are neither visual nor motor in the usual sense. Like visual cells, QV cells respond vigorously, reliably, and with constant latency to the appearance of a visual stimulus in the receptive field. This response occurs regardless of whether the appearance of the stimulus in the receptive field is followed by a saccade to that stimulus, to another stimulus, or by no saccade at all. Unlike visual cells, QV cells also discharge before certain saccades on doublesaccade trials even though a visual stimulus never appeared in the receptive field. Also, unlike visual cells, QV cells may show prolonged activation to very brief stimulus presentations (20-80 ms). This extended activation does not appear to be due to visual factors alone. Brief stimuli elicit short-duration discharges if the stimulus is not a saccade target (Fig. $8 B$ ), but much longer discharges if the stimulus is a saccade target (Figs. 9B, 11).

Like most SR cells, QV cells discharge reliably prior to certain saccades even when a visual stimulus did not appear in the receptive field. To activate a QV cell in this way, the saccade must have an amplitude and direction that corresponds more or less to the distance and direction of the receptive field from the fovea. The response of a QV cell differs from that of an SR cell in that neither the onset of the discharge nor the peak spike frequency are tightly linked to saccade onset. On double-saccade $(\mathrm{O} \rightarrow$ $\mathrm{B} \rightarrow \mathrm{C})$ trials, the discharge of $\mathrm{QV}$ cells typically begins after a saccade to the location where target B appeared. It is as if these cells are responding to a target (target C) that is no longer there. Can the discharge of QV cells on double-saccade trials be attributed to a residual trace of target $C$ caused by oscilloscope persistence? This explanation was rejected for the following reasons: 1) The $\mathrm{P} 47$ phosphor employed decays to $10 \%$ in less than $80 \mathrm{~ns}$; the P31 phosphor in less than $38 \mu \mathrm{s}$. 2) A lowcontrast target was used. Target intensity was low and background intensity was high. 3 ) On double-saccade trials, oscilloscope persistence failed to activate visual neurons, failed to produce a visual component in visual-motor neurons, and failed to activate visually dependent cells. 4) $\mathrm{O} \rightarrow \mathrm{B}$ control trials for the $\mathrm{O} \rightarrow \mathrm{B} \rightarrow \mathrm{O}$ double-saccade task show that the QV cell discharge on double-saccade trials cannot be attributed to oscilloscope persistence or to stray images being moved into the receptive field following the $\mathrm{O} \rightarrow \mathrm{B}$ saccade (see RESULTS). 5) $\mathrm{O} \rightarrow \mathrm{B} \rightarrow \overline{\mathrm{O}}$ brief target trials serve as an additional control for oscilloscope persistence. A brief-duration target at position $B$ required a saccade $(\mathrm{O} \rightarrow \mathrm{B})$ to position $\mathrm{B}$ and a second $(\mathrm{B} \rightarrow$ $O)$ saccade to the remembered location of $O$. If the $B \rightarrow O$ saccade had a particular direction and amplitude, a discharge of the QV cell preceded the saccade even though the initial fixation target $(\mathrm{O})$ had been extinguished for at least $140 \mathrm{~ms}$. 6) Some QV neurons began to discharge as soon as the eyes arrived at location B (22). Since, on single-saccade trials (whether or not a saccade is made), a neuronal discharge never occurs less than $70 \mathrm{~ms}$ after a target appears in the receptive field, this early activation of QV neurons cannot be accounted for by target persistence.

Some QV cell properties are similar to those of enhanced visual cells described by Wurtz and his co-workers $(7,25)$. 
According to these investigators, enhancement refers to the increase in vigor of a visual cell's discharge when the stimulus is also used as a saccade target. Two types of enhancement have been described; an early response that appears as an increased initial visual discharge and a late response that takes the form of a prolongation of the visual response. Typically, the late response persists until about $50 \mathrm{~ms}$ after the saccade. Enhancement was first thought to reflect an attentional or general target-selection function (7), but recently Wurtz and Mohler (25) have shown that the time of occurrence of enhancement can be manipulated by changing the timing of the signal to make a saccade. Late enhancement can be shifted so as to appear as early enhancement if the signal to make a saccade is anticipated. Since Wurtz and co-workers frequently give repeated presentations of the same trial type, a procedure that allows monkeys to anticipate the saccade trigger, much of the early enhancement may be due to anticipation of the signal to make a saccade. Wurtz and Mohler (25) concluded that enhancement results from activation of visual cells by those underlying SR cells that have a discharge very looscly coupled to saccades.

Although we have not directly tested for enhancement, there are similarities between QV and enhanced visual cells. Both are found at about the same depth in the SC. They are not the most superficial cells encountered but tend to be above most SR cells. We find a substantial number of QV cells at the level of or slightly below the first SR cells. About one-half of all visual cells recorded by Wurtz show enhancement; slightly more than one-half of our visually responsive cells are classified as QV cells. Late enhancement is a prolongation of a visual response until after a saccade to the stimulus occurs. All of our QV cells fire until a saccade to the visual stimulus occurs, even if the stimulus is very brief. Finally, the temporal course of enhancement is reported to parallel that of eye movements (25). Our double-saccade experiments indicate that much of the QV cell's discharge is also loosely coupled to the saccade.

At least some SC neurons showing the property of enhancement appear to be able to distinguish real from self-induced stimulus movement. Robinson and Wurtz (14) isolated visually responsive cells that discharged more vigorously to a visual stimulus moving across the receptive field than to a similar stimulus movement on the retina caused by a saccade. The mechanism of this discrimination appears to be a general suppression of the activity of many visually responsive cells that begins during or just after a saccade. This suppression is seen during eye movements in the dark and so appears to be extraretinal in origin. Most of the cells that showed this suppression also showed enhancement.

The discharge of QV cells also shows a reduction of activity after saccades. On $\mathrm{O} \rightarrow \mathrm{A}$ trials, QV cells always stopped firing just after the saccade to the target (see Figs. $7 A, 8 A, 9 A$ ). This cessation of activity could be due to the removal of the visual target from the receptive field by the saccade. However, when a brief target elicits a saccade (as in Fig. 9B), QV cells cease firing after the saccade to the target, not after stimulus offset. Similarly, on double-saccade trials (e.g., Figs. $7 D, 8 C$, $9 C) \mathrm{QV}$ cells stop firing after the final saccade to the target. A general reduction in QV activity following spontaneous saccades was also noted. The results of Robinson and Wurtz (14) suggest that the signal to cease firing may be extraretinal. We cannot address this question directly since we did not study the discharge of QV neurons during spontaneous saccades in the dark.

Whether or not some of the cells we have classified as QV are the same as the enhanced visual cells described by Wurtz and co-workers $(7,25)$, QV and enhanced visual cells appear to reflect similar processes. Both appear to be visually activated and also show a response that is neither purely sensory nor purely motor. Even though the discharge of these cells is not tightly linked to a saccade, the nonvisual component appears to be in a motor rather than a visual frame of reference.

\section{Linkage between visual and saccade- related activity}

The results of this investigation have important implications for questions of linkage between visual and SR cells. The 
correspondence of a retinotopic visual map in the superficial SC to an underlying motor map has strongly suggested a functional connection between them. In a simple model, visually responsive cells could activate SR cells just below them, which would, in turn, direct the fovea to the visual stimulus. The results of the present study provide little support for the view that there is an essential linkage between the activity of visual cells in superficial layers and deeper SR cells. The discharge of visual cells reflects retinal stimulation faithfully. Vigorous activity may occur in visual cells that does not become translated into discharges of underlying SR cells. Conversely, most SR cells discharge before all saccades within their movement ficlds, and the presence of a direct visual target has no effect on either the probability or vigor of an SR discharge. These results are consistent with other data, indicating that any interaction between superficial and deeper layers cannot occur in a simple or deterministic fashion. Previous experiments have shown that visual stimuli can activate superficial cells without generating saccades $(6,7,19)$. Furthermore, neurons in the intermediate and deeper layers generate bursts of activity prior to spontaneous saccades in the dark $(16,21,24)$. Presumably, these SR bursts are not preceded by discharges of more superficial visual neurons.

The existence of visually dependent SR cells does suggest a direct linkage between visual and underlying SR cells. Visually dependent SR cells require a visual stimulus adequate to activate corresponding visual cells as a prerequisite to SR activity. This is a property that would be expected if there were a close point-to-point linkage between visual and SR layers of the SC. Relatively few SR cells are visually dependent. Only 3 of 53 SR cells required a direct-saccade target to be activated and only 8 ( of 53) cells show any dimunition of the SR response in the absence of a direct target. These results agree with those of Mohler and Wurtz (11) who, when specifically searching for these cells, found only 10 of 79 cells that were visually triggered.

Anatomical evidence for connections between superficial and deep layers of the cat SC has recently been discussed by Edwards (4). Despite repeated efforts to demonstrate connections between superficial (strata griseum superficiale and opticum) and deep layers (strata griesea intermedium and profundum), Edwards found no convincing evidence for such connections. Sprague (23) found that small superficial layer lesions produced degeneration in deeper layers. However, in later autoradiographic tracing experiments, Edwards noted the possibility that the label seen in deeper layers after amino acid injections in superficial gray may be due to fibers of passage. Although it cannot be stated that all label in deeper layers is due to fibers of passage, the evidence for direct superficial to deep connections is equivocal. It should also be noted that the existence of visually evoked neuronal responses in deeper layers does not imply a superficial to deep connection; deeper layers of the $\mathrm{SC}$ receive projections from visual cortex and it has been shown that cooling of visual cortex abolishes visual responses of deeper layers while leaving intact the visual responses in the superficial layers (17).

\section{Retinocentric versus spatially organized saccades}

The question of whether saccades are programmed in a retinocentric or spatial frame of reference is closely related to the problem of sensorimotor linkage. A retinocentric model is far simpler and is even implied by the close correspondence of visual and motor maps of the SC $(12,16)$. In a retinocentric system, the position of the eye in the orbit (or indeed, the head in space) is irrelevant. A saccade target appears at some distance and direction from the fovea. The retinal-error signal is transferred more or less directly to an element of the oculomotor system, which is also in a retinocentric frame of reference. The command to this element is simply to move the eye a certain distance and direction. There is no need to take eye position into account since the command is not to move the eye to a specific location in the orbit. The case for a retinocentric system is especially compelling when considering the possible role of the $\mathrm{SC}$ in foveation. The superficial visual cells are retinotopically organized $(3,6,15)$. Both stimulation and recording experiments indicate that the deeper SR layers of the SC are also retino- 
centrically organized. Stimulation of a SC site elicits essentially the same saccade regardless of starting eye position (12). Similarly, the discharge of SR neurons is independent of initial eye position $(15,21$, 24). A close linkage between retinotopically organized visual layers and similarly organized SR layers would be compatible with a retinocentric model of saccade generation.

In addition to the data indicating little linkage between visual and SR layers, there is substantial evidence that a retinocentric model of saccade generation is incorrect. For example, it clearly is possible to make saccades on the basis of cues other than retinal error. Saccades can be made to remembered target positions in the dark $(1,10)$. Furthermore, secondary corrective saccades can occur when the subject looks to remembered target locations (1). Hallet and Lightstone (8) have shown that a subject can make a saccade to the location of a target that was bricfly flashed during a prior saccade. The computation of the saccade vector to the flashed target cannot be based on retinal error alone, nor can it be programmed before the first saccade. These results indicate that the subject is combining information about the position of the eye in the orbit with the retinal locus of stimulation to determine the vector of the subsequent saccade.

Additional evidence that targets are localized on the basis of both eye position and retinal error can be found in experiments that show that oculomotor control signals can influence the localization of a target with respect to the head or body. Skavenski, Haddad, and Steinman (18) applied a constant load to the eye that was counteracted by the extraocular muscles. This resulted in no significant change in eye position but the additional force produced by the extraocular muscles, if unopposed, would have resulted in several degrees of rotation in a direction opposite to the load. The perceived location of a visual target relative to the body shifted in a direction opposite to that of the load. These results are consistent with the idea that an efference copy of eye position is combined with retinal error to produce the perception of the target's location in space.

A spatial model is required if saccades are directed to a specific location in space and do not simply move the eye in a vector that reduces retinal error. In one such model proposed by Robinson and co-workers (2, $13,27)$, saccades to visual targets are computed as follows: First, the image of a visual target on the retina creates a retinal-error signal (i.e., the distance and direction of the target's projection from the fovea). Second, the retinal-error signal is added to an eyeposition signal (probably efference copy) to produce a neural representation of the target's location with respect to the head. Similar operations could also produce a representation in a body or world frame of reference. The fact that a saccade can be made to a remembered target location suggests that this representation of target location in space can be stored in memory. Third, eye-position error is computed by continuously subtracting the current eye position in the orbit from the location of the target with respect to the head. Thus, the cyc-position error will indicate, at any time, the distance and direction required of a saccade to direct the eyes toward the target. If there is no change in eye position between the time the target appears and the saccade to it, then retinal error and eye-position error are identical. If the position of the eye changes between the appearance of a target and its acquisition (as in double-saccade trials), then eye-position error and not retinal error will be the appropriate information for the saccadic system. This model implies that there are three representations of a visual stimulus to which a saccade is made. The first is a representation of the stimulus in terms of retinal error. The second representation may combine eye position with retinal error to form a map of the stimulus relative to the head. The third representation is that of eye-position error, the saccade vector required to foveate a target.

There are similarities between the neural elements suggested by Robinson's model and cells found in the SC. Results of the present experiment suggest that the SC contains a retinal-error signal, a representation of eye-position error, and a motor command to correct eye-position error. First, the location of cellular activity in the superficial layers is a map of retinal error. Second, as Keller (9) has suggested, QV cells display properties expected of neurons 
encoding an eye-position-error signal. On single-saccade trials, the location of QV cell activity appears to reflect a retinal-error signal, but on such trials retinal error and eye-position error are equivalent. On double-saccade trials in which there is a short-duration visual stimulus and a longlatency saccade (Fig. 9B), QV cell activity outlasts the stimulus duration. This would be expected if the activity of QV cells reflects eye-position error and not simply the presence of a visual stimulus. As soon as the eyes move, the eye-position error is changed and so the active QV cells cease firing after a short delay. On double-saccade trials, the site of $\mathrm{QV}$ cell activation shifts with changes in the eye position (see below). The shifts in QV cell activity are always to locations of the SC that are contiguous with SR areas which, if activated, would minimize eye-position error. Although QV cells require (directly or indirectly) information about eye position, there is nothing in their firing pattern that directly indicates eye position in the orbit. It should also be noted that, unlike the eye-position-error signal in the Robinson model, QV cell activity cannot directly control the duration of the saccadic-pulse generator since the offset of QV cell activity is not tightly coupled to the end of the saccade. Finally, the discharge of SR neurons appears to be a motor command to correct eye-position error. Except for visually dependent cells, SR cells discharge before saccades of particular directions and amplitudes on both single- and double-saccade trials. The discharge of these neurons is tightly coupled to saccade onset, even if changes in eye position have occurred since target appearance. Thus, the discharge of these SR neurons must occur after retinal error and eye-position signals have been combined to compute the necessary saccade vector. The location in the $\mathrm{SC}$ of the active $\mathrm{SR}$ neurons represents the saccade vector needed to correct eye-position error.

The roles of several types of SC neurons are illustrated in Fig. 12. The left side of Fig. 12 is a schematic representation of the discharge patterns of visual, QV, and SR cells during an $\mathrm{O} \rightarrow \mathrm{B} \rightarrow \overline{\mathrm{O}}$ double-saccade trial. Although the interpretations given the discharge patterns are speculative, the firing patterns summarized in these traces are not; they represent a composite of observations reported in this study. The right side of Fig. 12 shows the sites of activity associated with each trace.

With the eyes directed at the fixation target $(\mathrm{O})$, the onset of target $\mathrm{B}\left(20^{\circ}\right.$ to the right) elicits a response from superficial visual cells in the left SC (represented by site 1). This response (shown in trace 1) is short because the discharge of visual cells to brief targets is typically phasic. Target $\mathrm{B}$ also evokes a sustained response (trace 2 ) from a neighboring population of $Q V$ cells (site 2). Although the duration of target B is brief, the activity of $Q V$ cells functions as a latch, holding eye-position-error signal in spatial register until a saccade is made. The QV cells at site 2 will fire as long as a $20^{\circ}$ rightward saccade is needed. A saccade trigger could be combined with this QV error-position signal to activate a population of SR cells at site 4 (see trace 4 ), thereby eliciting a saccade to $B$. When the animal looks to $\mathrm{B}$, the eye-position-error signal is no longer " $20^{\circ}$ right," and so the activity of QV cells at site 2 will cease after a brief delay. When the eyes are directed at B, a saccade back to $O$ is required. The current eye position (i.e., the eyes directed at $\mathrm{B}$ ) is then subtracted from the remembered spatial location (in a head frame of reference) of $\mathrm{O}$. The result is an eye-position-error signal of " $20^{\circ}$ left," which is signaled by activation of QV cells at site 3 . These cells will remain active (trace 3 ) until a saccade trigger arrives, which can activate nearby SR cells (trace 5) at site 5, thereby producing a saccade back to $O$. This second saccade will cause the eye-position-error signal to be changed from $20^{\circ}$ left, and then QV cell activity at site 3 will cease shortly afterward.

Long-lead SR cells (not shown in Fig. 12) may represent an intermediate step in the transition from the QV eye-position-error signal to the burst of tightly coupled SR cells. Since long-lead SR cells seem to combine activity, which signals that a particular saccade is needed with a tightly linked SR burst, these cells may represent the point where a tentatively programmed saccade is combined with a saccade trigger to commit the eyes to move.

The suggestion that the discharge of QV cells represents an eye-position-error map and that SR neurons issue a command to 


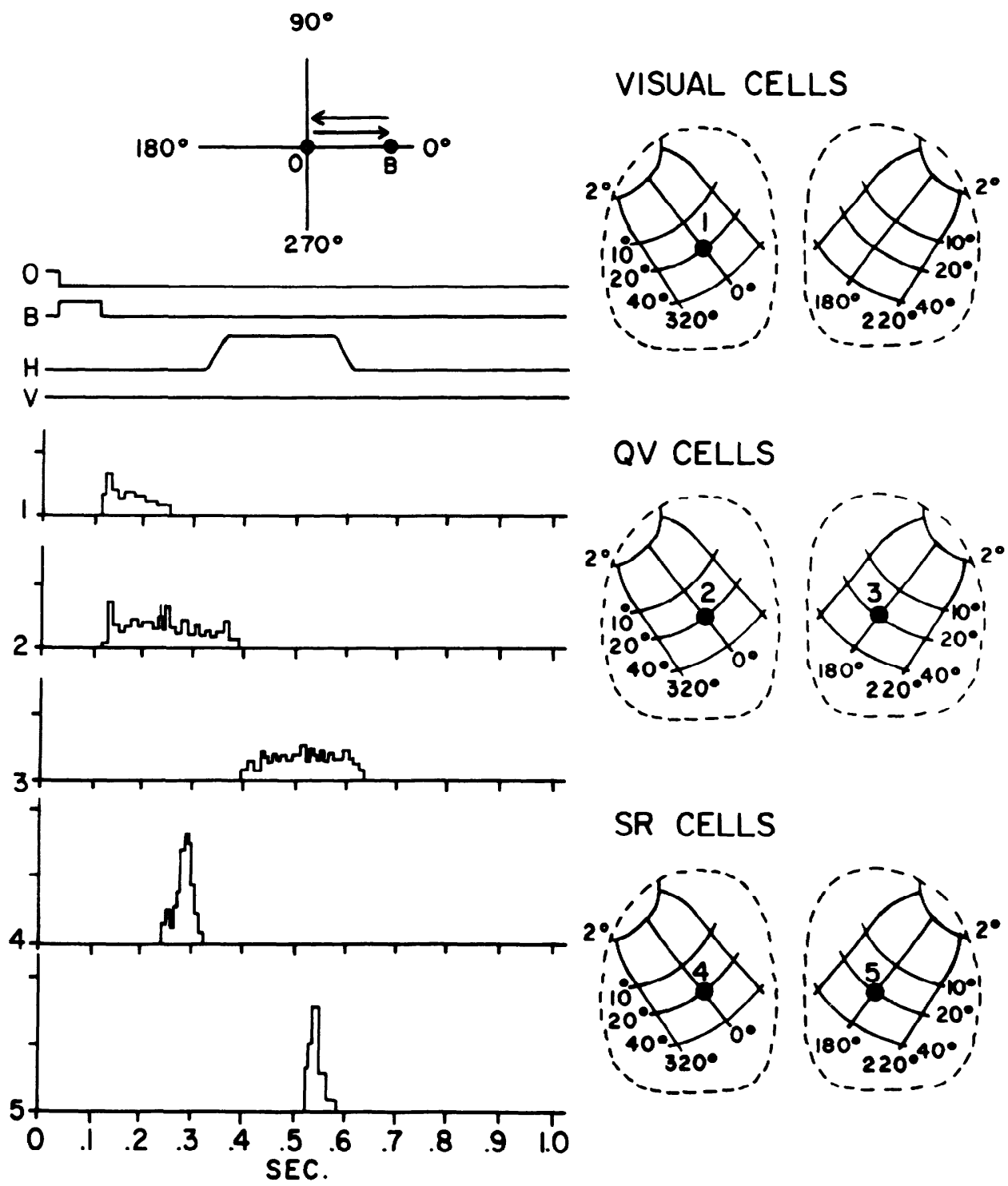

FIG. 12. Schematic representation of visual, QV, and SR cell activity on an $\mathrm{O} \rightarrow \mathrm{B} \rightarrow \overline{\mathrm{O}}$ double-saccade trial. This is not an actual record of five cells recorded on a single trial, but rather a composite intended to show activity patterns for these cell types on a double-saccade trial. Traces on the left show activity patterns of these cells, while the corresponding (1-5) filled circles show locations of cells. With eyes looking at 0 , the appearance of a brief visual target at $\mathrm{B}\left(20^{\circ}\right.$ to the right) will elicit a short-duration burst of activity from visual cells at site 1 and a longer period of activity from nearby QV cells at site 2. About 20-40 ms prior to the saccade to B, a SR cell (site 4 . trace 4) will begin a high-frequency burst of activity. Just after the saccade to B, the QV cells at site 2 will cease firing. Now that a (leftward) saccade back to $O$ is required, QV cells at site 3 (in the right SC) will begin to fire (trace 3). Thus the site of QV cell activation will have shifted from site 2 to site 3 . The saccade to $O$ is preceded by a burst from SR cells in the right SC (site 5, trace 5). Shortly thereafter, the QV cells at site 3 stop discharging.

correct this error does not address a number of crucial questions. There are, as yet, no promising hypotheses concerning the process of target selection. Moreover, the mechanism or loci for the transformation between retinocentric and nonretinocentric coordinate systems are unknown.

\section{CONCLUSIONS}

These results have important implications for attempts to describe the role of the SC in the control of saccadic eye movements. The presumed linkage, implicit in earlier versions of the foveation hypothesis (15), 
between the superficial layers (receiving direct retinal inputs) and the deeper layers of the SC is not necessary for the activation of SR neurons. Saccade-related burst neurons in the intermediate layers of the SC discharge without prior activation of superficial neurons signaling retinal position. The vigor of the SR discharge of some deeper neurons may be altered by the activity of superficial neurons, but the burst of most SR cells is unaffected by superficial layer activity.

The lack of a tight linkage between visual activity in the superficial layers and SR activity in the deeper layers is not unexpected. When the monkey is confronted with a complex visual scene, many regions of the retina and the corresponding regions of the SC are simultaneously activated. The selection of a particular target for foveal acquisition may depend on properties of the stimulus (size, shape, color, etc.) to which the visual neurons in the superficial layers of the SC are insensitive. Furthermore, saccades may be initiated by auditory, tactile, and other nonvisual cues such as the remembered location of a target, which may be in a head or body frame of reference.

Results of the present experiment indicate that the SC participates in saccades to targets localized using retinal-error and eyeposition cues. Models of SC function must be expanded to incorporate these findings.

\section{REFERENCES}

1. Becker, W. AND Fuchs, A. Further properties of the human saccadic system: eye movements and correction saccades with and without visual fixation points. Vision Res. 9: 1247-1258, 1969.

2. Chun, K. S. and Robinson, D. A. A model of quick phase generation in the vestibulocular reflex. Biol. Cybern. 28: 209-221, 1978.

3. Cynader, M. and Berman, N. Receptive-field organization of monkey superior colliculus. $J$. Neurophysiol. 35: 187-201, 1972.

4. EDwards, S. B. The deep cell layers of the superior colliculus: their reticular characteristics and structural organization. In: The Reticular Formation Revisited: Specifying Function for a Non-Specific System, edited by J. A. Hobson and M. A. B. Brazier. New York: Raven. In press.

5. Fuchs, A. F. and Robinson, D. A. A method for measuring horizontal and vertical eye movement chronically in the monkey. J. Appl. Physiol. 21: $1068-1070,1966$.

6. Goldberg, M. E. And Wurtz, R. H. Activity of superior colliculus in behaving monkey. I. Visual receptive fields of single neurons. J. Neurophysiol. 35: $542-559,1972$
One scheme for doing so is as follows. The discharge of saccade-related burst neurons in the deeper layers of the SC represents a motor command to correct eye-position error. These neurons may be accessed by a variety of inputs. For example, on singlesaccade trials, they may be activated by signals in a retinal frame of reference utilizing visually dependent neurons. However, they may also be activated by signals in a head or body frame of reference (such as auditory or somatosensory signals) or by higher order signals such as the memory of the spatial location of a target utilizing QV neurons. According to this view, inputs to the SC (whether they be in a retinal or nonretinal frame of reference) capable of initiating particular saccades must terminate according to the restrictions imposed by the motor map of the SC.

\section{ACKNOWLEDGMENTS}

We thank Sally Marcus and Richard Holland for technical assistance and Dr. Terry Hickey for preparing histological sections. Computer programs for behavioral training and data acquisition and analysis were developed by Richard Sheetz.

This research was supported by National Institutes of Health Grant EY01189 to D. L. Sparks.

L. E. Mays was supported by a National Institute of Mental Health Training Grant, 1 T32MH14286.

Received 12 October 1978; accepted in final form 2 July 1979.
7. Goldberg, M. E. And Wurtz, R. H. Activity of superior colliculus in behaving monkey. II. Effect of attention on neuronal responses. J. Neurophysiol. 35: 560-574, 1972.

8. Hallet, P. E. And Lightstone, A. D. Saccadic eye movements toward stimuli triggered by prior saccades. Vision Res. 16: 99-106, 1976.

9. Keller, E. L. Colliculoreticular organization in the oculomotor system. Progr. Brain Res. In press.

10. Komoda, M. K., Festinger, L., ANd Sherry, J. The accuracy of two-dimensional saccades in the absence of continuing retinal stimulation. Vision Res. 17: 1231-1232, 1977.

11. Mohler, C. W. and Wurtz, R. H. Organization of monkey superior colliculus: intermediate layer cells discharging before eye movements. $J$. Neurophysiol. 39: 722-744, 1976.

12. Robinson, D. A. Eye movements evoked by collicular stimulation in the alert monkey. Vision Res. 12: 1795-1808, 1972.

13. Robinson, D. A. Oculomotor control signals. In: Basic Mechanisms of Ocular Motility and Their Clinical Implications, edited by P. Bach-y-Rita 
and G. Lernerstrand. London: Pergamon, 1975, p. 337-374.

14. Robinson, D. L. AND Wurtz, R. H. Use of an extraretinal signal by monkey superior colliculus ncurons to distinguish real from self-induced stimulus movement. J. Neurophysiol. 39: 852870, 1976.

15. Schiller, P. H. And Koerner, F. Discharge characteristics of single units in superior colliculus of the alert rhesus monkey. J. Neurophysiol. 35: 920-936, 1971.

16. Schiller, P. H. and Stryker, M. Single-unit recording and stimulation in superior colliculus of the alert rhesus monkey. J. Neurophysiol. 35: 915-924, 1972.

17. Schiller, P. H., Stryker, M., Cynader, M., AND BERMAN, N. Response characteristics of single cells in the monkey superior colliculus following ablation or cooling of visual cortex. $J$. Neurophysiol. 37: 181-194, 1974.

18. Skavenski, A. A., Haddad, G., and Steinman, R. M. The extraretinal signal for the visual perception of direction. Percept. Psychophys. 11: 287-290, 1972.

19. SPARKS, D. L. Functional properties of neurons in the monkey superior colliculus: coupling of neuronal activity and saccade onset. Brain Res. 156: $1-16,1978$.

20. Sparks, D. L. and Holland, R. Computer control of eye position and velocity. Behav. Res. Methods Instrum. 7: 115-119, 1975.
21. Sparks, D. L., Holland, R., and Guthrie, B. L. Size and distribution of movement fields in the monkey superior colliculus. Brain Res. 113: 21-34, 1976.

22. Sparks, D. L., Mays, L. E., and Pollack, J. G. Saccade-related unit activity in the monkey superior colliculus. In: Control of Gaze by Brain Stem Neurons, edited by R. Baker and A. Berthoz. Amsterdam: Elsevier/North-Holland Biomedical, 1977, p. 437-444.

23. Sprague, J. M. Mammalian tectum: intrinsic organization, afferent inputs, and integrative mechanisms. Neurosci. Res. Progr. Bull. 13: 204-213, 1975.

24. Wurtz, R. H. And Goldberg, M. E. Activity of superior colliculus in behaving monkey. III. Cells discharging before eye movements. J. Neurophysiol. 35: 575-586, 1972.

25. Wurtz, R. H. and Mohler, C. W. Organization of monkey superior colliculus: enhanced visual response of superficial layer cells. J. Neurophysiol. 39: 745-765, 1976.

26. Zahn, J. R., Abel, L. A., And Dell'Osso, L. F. Audio-ocular response characteristics. Sensory Processes 2: 32-37, 1978.

27. Zee, D. W., Optican, L. M., Cook, J. D., Robinson, D. A., And Engel, W. K. Slow saccades in spinocerebellar degeneration. Arch. Neurol. 33: 243-251, 1976. 